Claremont Colleges

Scholarship@ Claremont

All HMC Faculty Publications and Research

HMC Faculty Scholarship

4-1-1998

\title{
Energy Absorption During Running by Leg Muscles in a Cockroach
}

\author{
Robert J. Full \\ University of California - Berkeley \\ Darrell R. Stokes \\ Emory University \\ Anna N. Ahn \\ Harvey Mudd College \\ Robert K. Josephson \\ University of California - Irvine
}

\section{Recommended Citation}

Full, RJ, Stokes, DR, Ahn, AN, Josephson, RK. Energy absorption during running by leg muscles in a cockroach. J Exp Biol. 1998;201(7): 997-1012.

This Article is brought to you for free and open access by the HMC Faculty Scholarship at Scholarship @ Claremont. It has been accepted for inclusion in All HMC Faculty Publications and Research by an authorized administrator of Scholarship @ Claremont. For more information, please contact scholarship@cuc.claremont.edu. 


\title{
ENERGY ABSORPTION DURING RUNNING BY LEG MUSCLES IN A COCKROACH
}

\author{
ROBERT J. FULL ${ }^{1}, *$, DARRELL R. STOKES ${ }^{2}$, ANNA N. AHN ${ }^{1}$ AND ROBERT K. JOSEPHSON 3 \\ ${ }^{1}$ Department of Integrative Biology, University of California at Berkeley, Berkeley, CA 94720, USA, ${ }^{2}$ Department of \\ Biology, Emory University, Atlanta, GA 30322, USA and ${ }^{3}$ School of Biological Sciences, University of California at \\ Irvine, Irvine, CA 92697, USA \\ *e-mail: rjfull@socrates.berkeley.edu
}

Accepted 20 January; published on WWW 5 March 1998

\begin{abstract}
Summary
Biologists have traditionally focused on a muscle's ability to generate power. By determining muscle length, strain and activation pattern in the cockroach Blaberus discoidalis, we discovered leg extensor muscles that operate as active dampers that only absorb energy during running. Data from running animals were compared with measurements of force and power production of isolated muscles studied over a range of stimulus conditions and muscle length changes. We studied the trochanter-femoral extensor muscles 137 and 179, homologous leg muscles of the mesothoracic and metathoracic legs, respectively. Because each of these muscles is innervated by a single excitatory motor axon, the activation pattern of the muscle could be defined precisely. Work loop studies using sinusoidal strains at $8 \mathrm{~Hz}$ showed these trochanter-femoral extensor muscles to be quite capable actuators, able to generate a maximum of $19-25 \mathrm{~W} \mathrm{~kg}^{-1}$ (at $25^{\circ} \mathrm{C}$ ). The optimal conditions for power output were four stimuli per cycle (interstimulus interval $11 \mathrm{~ms}$ ), a strain of approximately $4 \%$, and a stimulation phase such that the onset of the stimulus burst came approximately half-way through the lengthening phase of the cycle. High-speed video analysis indicated that the actual muscle strain

potentials per cycle, with the timing of the action potentials such that the burst usually began shortly after the onset of shortening. Imposing upon the muscle in vitro the strain, stimulus number and stimulus phase characteristic of running generated work loops in which energy was absorbed $\left(-25 \mathrm{~W} \mathrm{~kg}^{-1}\right)$ rather than produced. Simulations exploring a wide parameter space revealed that the dominant parameter that determines function during running is the magnitude of strain. Strains required for the maximum power output by the trochanter-femoral extensor muscles simply do not occur during constant, average-speed running. Joint angle ranges of the coxa-trochanter-femur joint during running were 3-4 times greater than the changes necessary to produce maximum power output. None of the simulated patterns of stimulation or phase resulted in power production when strain magnitude was greater than $5 \%$. The trochanterfemoral extensor muscles 137/179 of a cockroach running at its preferred speed of $20 \mathrm{~cm} \mathrm{~s}^{-1}$ do not operate under conditions which maximize either power output or efficiency. In vitro measurements, however, demonstrate that these muscles absorb energy, probably to provide control of leg flexion and to aid in its reversal.
\end{abstract} during running was $12 \%$ in the mesothoracic muscles and $16 \%$ in the metathoracic ones. Myographic recordings during running showed on average 3-4 muscle action

Key words: locomotion, biomechanics, running, insect, arthropod, cockroach, Blaberus discoidalis.

\section{Introduction}

Muscles involved in locomotion are commonly regarded as actuators that do work and generate mechanical power. As Hill stated in 1950 'Each muscle is designed for maximal power and efficiency in its important range of speed'. Strong support for the view that muscles function in the ranges of speed, frequency, force, position on the length-tension curve or temperature that generate maximum power output comes from a variety of studies on swimming (Rome et al. 1988, 1993), running (James et al. 1995), flying (Stevenson and Josephson, 1990), sound production (Rome et al. 1996), sensing (Josephson and Stokes, 1994), pumping blood (Layland et al. 1995; Syme, 1993), breathing (Altringham and Young, 1991;
Syme and Stevens, 1989) and, in particular, ballistic activities such as jumping (Lutz and Rome, 1994).

Of course, muscles can serve functions in addition to acting as force, work and power generators. Musculo-skeletal complexes can also act as springs that store and return energy or as damping elements that absorb energy (Zajac, 1989). Although often acknowledged, evidence supporting the functioning of musculo-skeletal complexes as control elements, stabilizers and energy transfer units during locomotion is scarce. However, reports of musculo-skeletal complexes acting as more than simple power generators during locomotion are emerging as the technology allows us to mimic 
in vivo conditions or to make direct in vivo measurements. For example, Tu and Dickinson (1994) have discovered that some fly muscles actively absorb energy to control steering. Roberts et al. (1997) have shown that, during running, the gastrocnemius muscle-tendon complex of turkeys functions as an active spring generating force, but produces very little power. Fish may use caudal muscles to transmit energy generated more anteriorly to their tail fin (van Leeuwen et al. 1990; Altringham et al. 1993; Johnston et al. 1995; Videler and Hess, 1984; Wardle et al. 1995).

It is becoming increasingly evident that, to understand muscle function in a multiple muscle system, at least two data sets are desirable for each muscle. First, the capacity of the muscle should be determined in vitro and in simulation under a wide range of stimulation pattern, strain and activation phase. These data would produce a functional space of the potential performance of the muscle. Second, measurements of realized muscle function are essential in as many behaviors as possible, either in vivo or under in vitro conditions mimicking the muscle's function in vivo.

The present study addresses both potential and realized function. First, we characterized a muscle's potential to generate mechanical power by using the work loop method originated by Boettinger (1957) and Machin and Pringle (1960) on asynchronous flight muscle and extended by Josephson $(1985,1993)$ to synchronous muscle. We imposed cyclic length changes on a semi-isolated muscle while measuring force and then searched for the optimal muscle length, strain, stimulation phase and pattern. We also produced computersimulated work loops to estimate the potential for muscle work over a broader parameter space. Second, we estimated the muscle's realized function during locomotion. We used videographic analysis, dissection and simulation to determine the actual strain experienced by the muscle. Electromyographic recordings gave us the pattern with which the muscle was activated by neural input during locomotion. Using the work loop technique with realized strain and stimulation pattern, we tested the frequently proposed hypothesis that muscles in vivo, during locomotion, operate near the conditions that result in the generation of maximum mechanical power output in vitro.

To explore the possible diversity of muscle function in a multiple muscle system, we chose to examine constant, average-speed running. Constant, average-speed running is characterized by accelerations of the body or center of mass being matched by nearly equal decelerations over a complete stride. Energy absorption, storage and transmission by the musculo-skeletal system during running can be as important as energy production (Alexander, 1988; Cavagna et al. 1977). In contrast, substantial accelerations during swimming or flying are resisted by the medium and can require substantial muscle power production, while decelerations can be assisted by the medium. Selecting running as the locomotor mode, as opposed to swimming or flying, might increase the probability of discovering a wider range of diversity in muscle function (Alexander, 1997).

We chose to study dynamically running cockroaches
(Blaberus discoidalis) for several important reasons. Cockroaches run in a manner surprisingly similar to other legged animals. The mechanical energy generated to move $1 \mathrm{~g}$ of body mass over $1 \mathrm{~m}$ (Full and Tu, 1990, 1991), the massspecific mechanical energy produced to swing the limbs (Kram et al. 1997), whole-body ground reaction force patterns (Full, 1989; Full and Tu, 1990, 1991) and even relative leg spring stiffness are indistinguishable from data on bipedal runners and hoppers and on quadrupedal trotters (Blickhan and Full, 1993). Interestingly, even though three legs of the cockroach sum to function as one leg of a biped or two legs of a quadruped, each leg pair of a cockroach functions in a different way (Full et al. 1991, 1995). The front (prothoracic) pair of legs only decelerates the insect during the stance phase, while at the same time the hind (metathoracic) pair of legs only accelerates the animal forward. The middle (mesothoracic) pair of legs works much like human legs, since they first decelerate and then accelerate the body during a step. This separation of leg function could make cockroaches a unique model for demonstrating a muscle's full range of function. We began our characterization of muscle function by examining homologous muscles in each of the three leg pairs.

The exoskeleton of arthropods makes the determination of musculoskeletal strain and the recording of electromyograms (EMGs) relatively simple. The origins of individual muscles can be precisely located on the exoskeleton and used for accurate EMG electrode insertion. The exoskeleton also provides a rigid surface for the placement of markers that are visible during high-speed videography. The joint we selected (coxal-trochanteral-femoral joint) is a simple joint with one degree of freedom. Joint angles can be related unambiguously to musculo-apodeme length. Since arthropod apodemes are 40 times as stiff as mammalian tendons (Ker, 1977; Full and Ahn, 1995), joint angles can also be directly related to muscle length.

Most importantly, we chose insect leg muscles (muscles 87, 137 and 179) because they are innervated by a single motor axon (Pipa and Cook, 1959), which allows precise definition of both the duration and pattern of neural input. Muscles of most systems examined thus far have many motor units, and EMG recordings give information on the duration of the input, but not on the pattern of activation (number of arriving impulses or intervals between impulses), for individual motor units.

Finally, a large number of parameters affect the mechanical power of muscle. Dealing with this multidimensional parameter space can be a major difficulty in work loop studies. Limits on experimental time and deterioration of the preparation generally prevent full analysis of all possible permutations of parameter values (Josephson and Stokes, 1994). Fortunately, Full and Ahn (1995) have developed a three-dimensional musculo-skeletal model of the leg of $B$. discoidalis itself. To best define the muscle's potential and its in vivo point of operation during running, we complemented our experimental studies with work loop simulations of its parameter space. 


\section{Materials and methods}

\section{Muscles}

Blaberus discoidalis were obtained as adults from a commercial supplier (Carolina Biological Supply Co., PO Box 187, Gladstone, OR 97027, USA). The cockroaches were maintained in the laboratory in large, closed containers where they had free access to food (dried dog food) and water. The muscles selected for study were anterior extensor muscles 87 , 137 and 179 (notation of Carbonell, 1947). These are homologous muscles in the pro-, meso- and metathoracic segments, respectively. They originate on the proximal coxal margin and insert on the trochanter. They extend the coxaltrochanteral-femoral joint and thus depress the femur. Each of these muscles, together with their associated posterior depressor muscles (muscles 86, 136 and 178), is innervated by a single excitatory axon (Pipa and Cook, 1959), and there is no inhibitory innervation (Pearson, 1972; Pearson and Iles, 1971).

\section{Muscle strain during running}

An animal was immobilized by chilling, and white reference markers were painted on the ventral surface of the legs of one side to aid in measurement of joint angles. Three spots were placed on each leg: one on the proximal coxa just medial to the ventral condyle (i.e. hinge point), one on the trochanter, and one on the distal end of the femur (see Fig. 1). After they had recovered from immobilization, the animals were allowed to run in a glass-bottomed trough approximately $65 \mathrm{~cm}$ long and $25 \mathrm{~cm}$ wide. S-VHS video recordings were made of the running animals using a high-speed video system (NAC HSV400) at 200 fields $s^{-1}$. The animals were video-taped from below, using a front-surfaced mirror, to obtain a ventral view.
The video tapes were digitized and analyzed using a motion analysis system (Peak Performance Technologies, Inc.) to obtain the time course of coxal-trochanteral-femoral angle changes for each of the three legs on one side of the animal's body.

The relationships between coxal-trochanteral-femoral angle and muscle length were determined empirically using a different set of animals from those filmed during running, but of comparable body mass. Reference spots, positioned similarly to those used in video-taping, were painted on each leg of one side of a narcotized (chilled) animal. The thoracic segments with the attached legs were then isolated and pinned, ventral side up, in a dissecting dish. The femur of the marked side was left free to rotate about the coxal-trochanteral-femoral joint. A small window was cut through the coxal exoskeleton overlying the muscle insertion to expose a characteristic pigmented spot on the muscle apodeme. The muscle reference length was taken as the length of the muscle when its moment arm was perpendicular to the long axis of the coxa. This length was the distance between the medial insertion of the muscle and the pigmented spot on the apodeme measured after adjusting the coxal-trochanteral-femoral angle such that (1) a line joining the ventral condyle (i.e. hinge point) of the coxaltrochanteral-femoral joint and the insertion of the muscle (marked by a slight depression on the trochanter) was perpendicular to (2) a line drawn between the coxaltrochanteral condyle and the ventral condyle of the joint between the coxa and the thoracic body segment (Fig. 1). Changes in muscle length were determined by measuring, using an ocular micrometer (resolution $20 \mu \mathrm{m}$ ), changes in the distance between the pigmented spot on the muscle apodeme and the medial edge of the hole in the exoskeleton made to
Fig. 1. The relationships between coxalfemoral joint angle $(\beta)$ and muscle length in pro-, meso- and metathoracic limbs. The dark spots on the limbs are the positions of the reference points used in measuring joint angle. The locations of the muscles studied are shown as shaded regions in the drawings. The different symbols in the graphs indicate results from different animals. No significant effect of individual was found, so the data points were treated as independent. See text for the definition of reference length. Equations for the regression lines are given in the text.
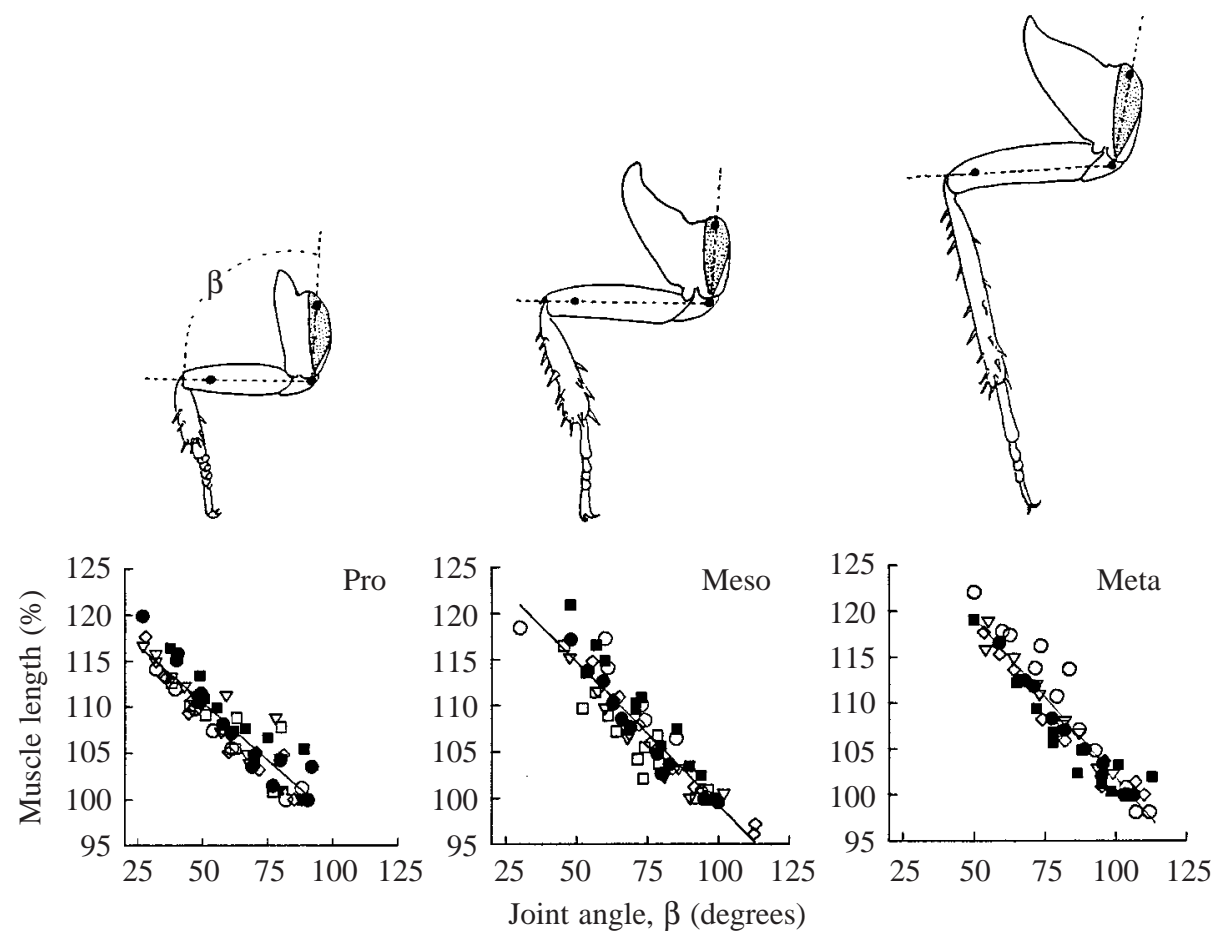
expose the spot. Changes in muscle length were determined at a number of coxal-trochanteral-femoral joint angles as defined by the painted spots on the legs. The relationship between joint angle and muscle length was determined for six pro-, mesoand metathoracic muscles, three from male and three from female animals. In general, the relationship between joint angle and muscle length was linear for the range of joint angles likely to occur during running (Fig. 1). The specific relationships between muscle length, $L$, as a percentage of the reference length and joint angle, $\beta$, measured in degrees, were:

$$
\begin{array}{ll}
L_{\text {prothoracic }}=122.9-0.248 \beta & \left(r^{2}=0.86\right), \\
L_{\text {mesothoracic }}=131.6-0.321 \beta & \left(r^{2}=0.84\right), \\
L_{\text {metathoracic }}=136.9-0.350 \beta & \left(r^{2}=0.90\right) .
\end{array}
$$

These data are consistent with values obtained from a threedimensional musculo-skeletal model (Full and Ahn, 1995). These equations were used to convert the time course of changing joint angle, determined from the video recordings, to muscle strain.

Muscle length changes had broad maxima and minima (Fig. 2), so it was difficult to define precisely a length cycle based on the times of successive maximum lengths or minimum lengths. Mid-length times, which could be measured with some precision, were used to establish the boundaries of a cycle. Mid-length was defined as the mean of the maximum and minimum lengths attained in a cycle. Mid-length time (i.e. cycle start or end time) was determined by linear interpolation between the times corresponding to the measured length values immediately bracketing the calculated mid-length.

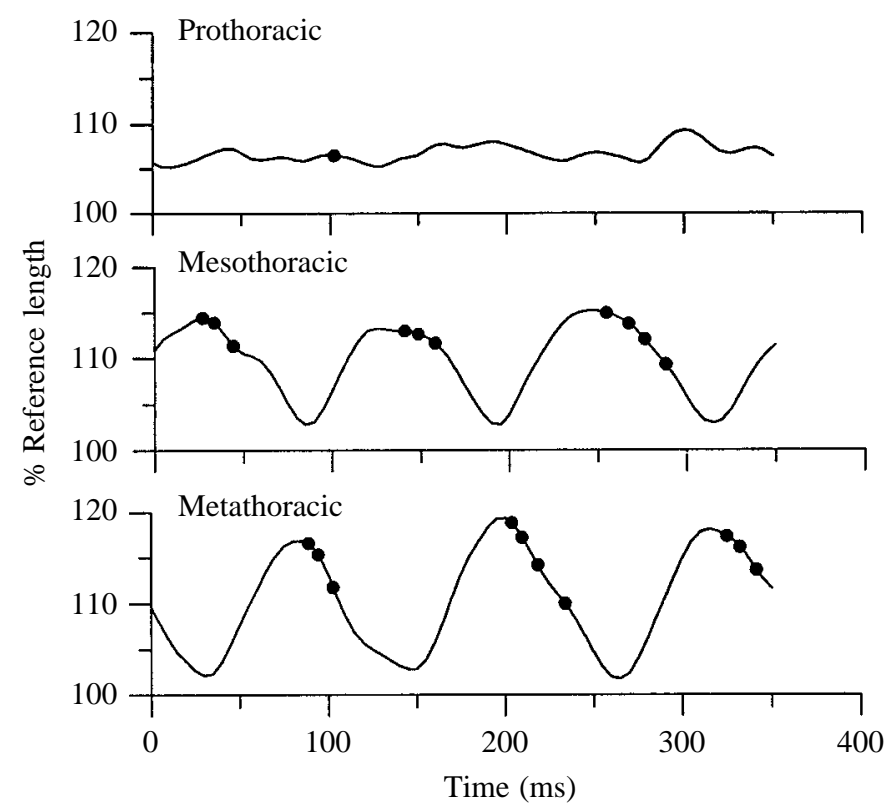

Fig. 2. Muscle length and muscle action potentials (MAPs) in a running animal. The muscle lengths were calculated from measured joint angles during running using the linear relationship determined between joint angle and muscle length (Fig. 1). The filled circles indicate the time of occurrence of MAPs during these recordings.
Specifically, if $L_{\mathrm{i}}$ and $t_{\mathrm{i}}$ were the muscle length and frame time for the video frame taken immediately before the muscle length reached the calculated mid-length $\left(L_{\mathrm{m}}\right)$ during muscle lengthening, and if $L_{\mathrm{i}+1}$ and $t_{\mathrm{i}+1}$ were the corresponding length and time for the following frame, then the mid-length time (the time of cycle onset) is given by $t_{\mathrm{i}}+\left(\mathrm{t}_{\mathrm{i}+1}-t_{\mathrm{i}}\right) \times\left(L_{\mathrm{m}}-L_{\mathrm{i}}\right) /\left(L_{\mathrm{i}+1}-L_{\mathrm{i}}\right)$.

\section{Recording muscle action potentials}

Recording electrodes were implanted into the coxal depressor muscles of the animals while they were immobilized. Insulated silver wires, $50 \mu \mathrm{m}$ in diameter and cut to a length of approximately $30 \mathrm{~cm}$, were heated at one end in a flame to remove the insulation and to melt the end of the wire to form a small ball. A hole, slightly smaller than the silver ball, was made through the coxal exoskeleton with a sharpened insect pin. The hole was positioned directly over the origin of the muscle. The ball at the end of the wire was forcibly pushed through the hole and then gently pulled back to engage the ball against the inside edge of the hole. The wire was then fixed to the coxa, the dorsal tergum and the prothoracic shield using low-melting-point dental wax and a small, heated probe. Recording electrodes were placed in the muscles of the relevant pro-, meso- and metathoracic legs.

A reference and a ground electrode, each made of thin, uninsulated silver wire, were inserted separately through the dorsal exoskeleton into the first abdominal segment, waxed in place, and then brought forward to the pronotal shield, where they were again waxed in place. The electrode wires from the three muscles, and from the reference electrode and the ground electrode, were fixed together with model cement to form a single, long tether. The combined mass of the wires and the wax used to fix them to the animal averaged $60.1 \mathrm{mg}(N=11)$, which was less than $2 \%$ of the mean body mass $(3.7 \mathrm{~g}, N=6)$ of the animals from which successful recordings were obtained. Muscle action potentials (MAPs) recorded from the running animals were amplified 100 times at a bandwidth of $3 \mathrm{~Hz}$ to $1 \mathrm{kHz}$ and were recorded with an FM data recorder (TEAC XR-700). A pulse generator provided coded output which was stored on both the FM recordings and the video tapes of running animals to allow synchronization of EMG and video signals.

\section{Isometric force}

Animals were immobilized by chilling and mounted, ventral side up, in a Lucite holder that restrained the body and provided a platform to which the meso- or metathoracic coxae could be firmly attached using fast-setting, epoxy cement. The contractile properties of muscle 87 of the prothorax were not examined because this muscle was found to be inactive during running (Fig. 3). A small piece of the proximal trochanter and the attached muscle insertion was dissected free from the leg. Muscle force was measured with a transducer constructed from a pair of silicon semi-conductor strain gauges (see Fig. 4.4 in Miller, 1979). A small hook, fashioned from a sharply bent insect pin, was fixed to the transducer. The hook was slid around the muscle apodeme between the muscle and the 


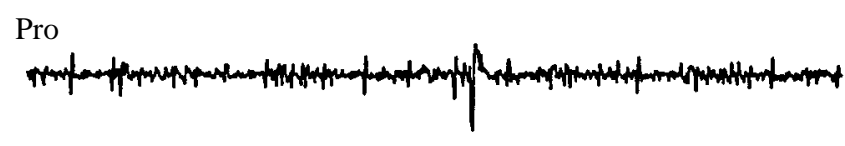

Meso
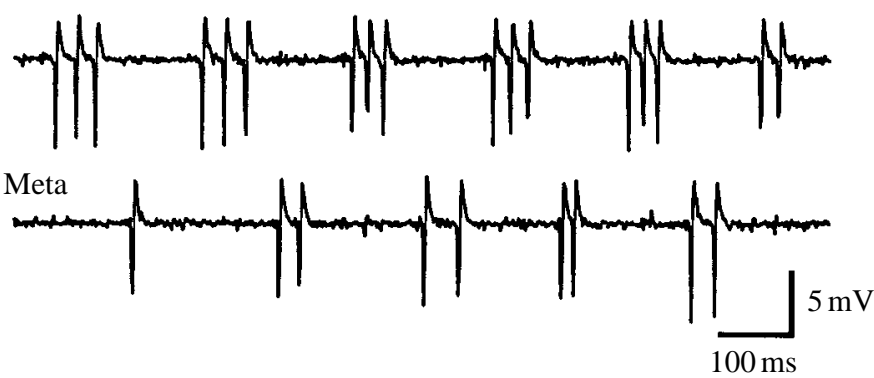

Fig. 3. Electromyogram (EMG) recordings from trochanter-femoral extensor muscles 87 (prothoracic, Pro), 137 (mesothoracic, Meso) and 179 (metathoracic, Meta) of Blaberus discoidalis during rapid running. This segment of the recording from the prothoracic channel includes a single large action potential amid low-amplitude background activity probably originating from adjacent muscles.

attached piece of cuticle to link the muscle to the transducer. The transducer was mounted in a manipulator which allowed adjustment of muscle length. Measurements were made with the muscle at its in vivo length as judged by the position of the muscle insertion relative to that of surrounding structures.

The exoskeleton was removed from over the appropriate thoracic ganglion. Nerve 5, which includes the motor axon to the muscle, was exposed and sectioned near the ganglion. The nerve was stimulated with $0.5 \mathrm{~ms}$ shocks at approximately twice threshold. The stimuli were delivered through a suction electrode over the cut end of the nerve. The stimuli were single shocks, trains of 2-6 stimuli at 10 or $11 \mathrm{~ms}$ interstimulus intervals, and tetanic bursts at $100-200 \mathrm{~Hz}$ for $300 \mathrm{~ms}$. Stimulus trials were repeated regularly at $30 \mathrm{~s}$ intervals. The nerve and the muscle were moistened periodically with insect saline (composition given in Becht et al. 1960). Muscle temperature was monitored with a thermistor probe placed adjacent to the muscle. The output of the temperature probe provided the input signal to a servosystem which held the muscle temperature constant at $25^{\circ} \mathrm{C}$ by adjusting the intensity of a microscope lamp whose beam was directed at the muscle. Mechanical responses were collected using an analog-todigital converter and stored on magnetic disks.

At the end of an experiment, the muscle was fixed with $70 \%$ ethanol while it was still attached to the strain gauge. Ethanol fixation both stabilized the muscle length, so that it did not change when the muscle was released from the transducer, and simplified dissection of the muscle from its cuticular attachments. The length of the dissected muscle was measured, after which the muscle was stored in $70 \%$ ethanol. After several days in ethanol, the muscle was rehydrated overnight in insect saline and weighed. The loss of muscle weight associated with fixation and rehydration was determined in a set of control muscles. Mesothoracic muscles 137 and 138 and metathoracic muscles 178 and 179 were removed bilaterally
Table 1. Size of trochanter-femoral extensors 137

(mesothoracic) and 179 (metathoracic) of Blaberus discoidalis

\begin{tabular}{lccc}
\hline & $\begin{array}{c}\text { Mass } \\
(\mathrm{mg})\end{array}$ & $\begin{array}{c}\text { Length } \\
(\mathrm{mm})\end{array}$ & $\begin{array}{c}\text { Area } \times 10^{3} \\
\left(\mathrm{~cm}^{-2}\right)\end{array}$ \\
\hline Male & & & \\
$\quad$ Mesothoracic $(N=11)$ & $2.54 \pm 0.98$ & $4.32 \pm 0.45$ & $5.54 \pm 1.79$ \\
Metathoracic $(N=11)$ & $2.87 \pm 0.65$ & $4.48 \pm 0.65$ & $6.20 \pm 1.76$ \\
Female & & & \\
$\quad$ Mesothoracic $(N=10)$ & $2.78 \pm 1.31$ & $4.34 \pm 0.55$ & $6.16 \pm 2.23$ \\
$\quad$ Metathoracic $(N=12)$ & $3.12 \pm 1.17$ & $4.52 \pm 0.47$ & $6.80 \pm 2.05$
\end{tabular}

Values are given as mean \pm S.D.

The mesothoracic and metathoracic muscles came from different animals.

The mean mass of the 22 male animals was $2.73 \pm 0.51 \mathrm{~g}$; that of the 22 female animals was $3.69 \pm 0.66 \mathrm{~g}$ (mean \pm S.D.).

from four cockroaches. The muscles were weighed as bilateral pairs, fixed in $70 \%$ ethanol for several days, rehydrated and reweighed. The mean weight of these muscle pairs after fixation and rehydration was $95.1 \pm 1.1 \%$ (mean \pm S.E.M., $N=16$ muscle pairs) of that before fixation. The weights of the experimental muscles were therefore multiplied by $1 / 0.95=1.05$ to obtain the expected mass of the muscle before fixation. The cross-sectional area of the muscles used was estimated as the ratio of muscle mass to muscle weight (a muscle density of $1 \mathrm{gm} \mathrm{cm}^{-3}$ was assumed). The mass, length and area of the muscles used in this study are summarized in Table 1.

\section{Mechanical work output}

\section{General methods for obtaining work loops}

Animals were dissected and mounted as described above for force measurements except that the strain gauge was attached to the moving arm of an ergometer. The basic design of the ergometer is given in Malamud and Josephson (1991). The reference length of the muscle was determined following exposure of the apodeme but before the trochanteral exoskeleton and its attached muscle insertion were dissected free. The muscle was subjected to a series of trials consisting of 4-5 repetitions of cyclic strain and phasic stimulation in the strain cycle. Control signals to the ergometer for sinusoidal strain were generated by a purpose-built sine-wave generator; non-sinusoidal strain trajectories were produced by a computer which transmitted stored files through a digital-to-analog converter. Values of developed force and muscle length were collected with an analog-to-digital converter and analyzed on line. The work output per cycle was determined as the area of the loop formed by plotting muscle force against muscle length over a full cycle (Josephson, 1985). The third cycle of each trial was used for analyzing work output. Muscle temperature was maintained at $25^{\circ} \mathrm{C}$. At the end of each experiment, the muscle was fixed in ethanol and its length, mass and area were determined as described above. 


\section{Optimum parameters for work output}

An inconveniently large number of parameters affect the mechanical power output of a muscle undergoing periodic length change and phasic stimulation. The relevant parameters include cycle frequency, the resting length of the muscle, the pattern and amplitude of the cyclic strain imposed on the muscle, the number of stimuli per cycle, the phase and pattern in which these stimuli are delivered, the muscle temperature and the particular cycle chosen for analysis (Josephson, 1985). One goal in this study was to determine the maximum power that might be obtained from a muscle under conditions similar to those during rapid running. To make the task manageable, some of the parameters were set at values similar to those that pertained during running. The muscle temperature was held at $25^{\circ} \mathrm{C}$. The cycle frequency was $8 \mathrm{~Hz}$ and the interstimulus interval when there was more than one stimulus per cycle was $11 \mathrm{~ms}$. The pattern of strain imposed on the muscle was sinusoidal, as has been the case in many preceding work loop studies. The variables whose effects on work output were evaluated were the number of stimuli per cycle, the muscle resting length, the strain amplitude and the stimulus phase.

The number of stimuli per cycle was increased progressively from one to five in different sets of trials with some preparations and, in an equal number of preparations, decreased progressively from five to one. The following approach was used to identify the optimum parameters for work output with a given number of stimuli per cycle. Values were estimated for the muscle length and the cyclic strain that might be optimal for work output. Using these estimated optimal values for length and strain, the stimulus phase was varied systematically from trial to trial in steps of approximately $5 \%$ (one full cycle $=100 \% ; 0 \%$ phase defined as the time at mid-length during lengthening) until the optimum phase for those conditions was found. Next, using this optimum phase and the estimated value for optimal muscle length, the cyclic strain was varied systematically in steps of $0.02 \mathrm{~mm}$ (approximately $0.4 \%$ of the muscle length) to determine the optimum strain. If the value determined for optimum strain differed by more than one step from that originally estimated, the value for optimum stimulus phase was redetermined using the newly identified value for optimal strain and the estimated value for optimum length. Next, using the values determined for optimum stimulus phase and cyclic strain, the muscle length was varied systematically from trial to trial in steps of $0.1 \mathrm{~mm}$ (approximately $2 \%$ of muscle length) in order to find the optimal muscle length. If the value determined for optimal muscle length differed by more than one step from that initially estimated, the whole procedure for determining optimal phase, strain and muscle length was repeated, starting with the identified values for optimum length and strain.

\section{Maximum power output and realized power during running}

The procedures for identifying optimum stimulus phase, strain and mean muscle length for each of 1-5 stimuli per cycle were time-consuming (mean time $140 \pm 18$ min, mean \pm S.D.,
$N=12,1$ trial $\mathrm{min}^{-1}$ ). Frequently during this period there was some decline in the performance of the preparation, and the power output after many trials was less than that expected from a fresh muscle. Therefore, a new set of muscles was used to determine the maximum power output during sinusoidal strain. In these determinations, the conditions were set from the beginning at the mean values for optimal number of stimuli per cycle, muscle length, strain and stimulus phase determined as described above. A trial giving work loops at the optimal parameters was followed by a trial in which work output was determined under conditions simulating those during running. In the latter, the muscle was held at the length that had been determined to be the mean length during running and subjected to the strain pattern, stimulus number and stimulus phase found to pertain during running.

\section{Dynamic simulation of work during running}

We conducted a sensitivity analysis using a dynamic simulation to estimate the muscle's capacity in a wider parameter space. We used a three-dimensional model of the metathoracic leg of Blaberus discoidalis (Full and Ahn, 1995) and the modified Hill-type muscle model of Zajac (1989). We imposed the frequency and the strain pattern observed during running at the animal's preferred speed $\left(20 \mathrm{~cm} \mathrm{~s}^{-1}\right.$; frequency $8 \mathrm{~Hz}$ ) on muscle 179 . We varied the pattern of stimulation (1-6 MAPs with a constant $11 \mathrm{~ms}$ interstimulus interval), the phase of stimulation and the amplitude of the strain pattern. The values for the muscle variables used included: a maximum isometric force of $0.14 \mathrm{~N}$, an optimal length of $3.3 \mathrm{~mm}$, an apodeme slack length of $0.7 \mathrm{~mm}$ (Full and Ahn, 1995), a maximum contraction velocity of 5 muscle lengths $\mathrm{s}^{-1}$ and damping of $1 \mathrm{~N} \mathrm{~s} \mathrm{~m}^{-1}$ (estimated from Daniel, 1995; Meyhofer and Daniel, 1990). Damping was modeled as a velocitydependent component which decreased active and passive muscle fiber force. The effect of damping was linearly proportional to the magnitude of shortening velocity. We generated 594 simulated work loops, each of which yielded values for both work and power.

Results
Muscle strain and activation pattern during running
The sample set
Recordings of leg position and EMG activity from trials in
which the animals ran rapidly and straight without bumping
into the walls, and in which there were clean EMG recordings
from pro-, meso- and metathoracic muscles, were obtained
from six animals out of a starting set of nine. Four of the
animals were females (mean mass $3.86 \pm 0.51 \mathrm{~g}$; mean \pm S.D.)
and two were males ( $2.60 \mathrm{~g}$ and $3.16 \mathrm{~g})$. The data set presented
is based on two runs from each of five animals and one run
from the sixth animal. Two adjacent stride cycles were
analyzed in each run, except for one run which included only
a single complete metathoracic cycle. Thus, the data set
includes a total of 11 runs with 22 mesothoracic and 21
metathoracic cycles. The mean stride duration of the cycles

\section{Results}

he sample set

Recordings of leg position and EMG activity from trials in which the animals ran rapidly and straight without bumping into the walls, and in which there were clean EMG recordings from pro-, meso- and metathoracic muscles, were obtained from six animals out of a starting set of nine. Four of the animals were females (mean mass $3.86 \pm 0.51 \mathrm{~g}$; mean \pm S.D.) and two were males $(2.60 \mathrm{~g}$ and $3.16 \mathrm{~g})$. The data set presented is based on two runs from each of five animals and one run from the sixth animal. Two adjacent stride cycles were analyzed in each run, except for one run which included only includes a total of 11 runs with 22 mesothoracic and 21 metathoracic cycles. The mean stride duration of the cycles 
Table 2. Characteristics of the stride cycles analyzed

\begin{tabular}{lcccc}
\hline & $\begin{array}{c}\text { Cycle } \\
\text { duration } \\
(\mathrm{ms})\end{array}$ & $\begin{array}{c}\text { Mean } \\
\text { muscle } \\
\text { length } \\
(\% \mathrm{RL})\end{array}$ & $\begin{array}{c}\text { Total } \\
\text { strain } \\
(\% \mathrm{RL})\end{array}$ & $\begin{array}{c}\text { Shortening } \\
\text { duration } \\
(\% \text { cycle })\end{array}$ \\
\hline $\begin{array}{l}\text { Mesothoracic } \\
(N=22)\end{array}$ & $125.8 \pm 22.8$ & $104.7 \pm 2.8$ & $12.0 \pm 1.5$ & $60.4 \pm 6.30$ \\
$\begin{array}{l}\text { Metathoracic } \\
(N=21)\end{array}$ & $126.2 \pm 25.3$ & $104.4 \pm 3.4$ & $16.4 \pm 2.8$ & $60.0 \pm 8.6$ \\
& & & \\
\multicolumn{2}{l}{$\begin{array}{l}\text { Values are given as mean } \pm \text { S.D. } \\
\text { RL, reference muscle length (see text). }\end{array}$} & & \\
\hline
\end{tabular}

analyzed was approximately $125 \mathrm{~ms}$ (Table 2), which is a stride frequency of $8 \mathrm{~Hz}$. The range of stride frequencies in the whole data set was $5.9-12.3 \mathrm{~Hz}$. The mean speed was approximately $20 \mathrm{~cm} \mathrm{~s}^{-1}$, very near the animal's preferred speed (the most frequent speed selected by the animal during spontaneous running or running with minimal prodding).

\section{Muscle strain}

Length changes in the prothoracic muscle were small and variable, and muscle action potentials were rarely recorded during running (Figs 2, 3). Since prothoracic muscle 87 does not appear to be important in high-speed running, the prothoracic limb muscle will not be considered further.

To estimate the work done by the muscle during running, we generated a typical muscle strain trajectory for a stride cycle which could be used in work loop studies. Because the cycles varied in duration, it was not appropriate to create a 'typical' cycle by simply averaging values of relative muscle length at equal times after cycle onset. If this were done, the values for muscle length at long times after cycle onset would be determined entirely by the lengths of those muscles of the set with longer cycle durations, with no contribution at all from cycles that ended sooner than the time being considered. To compensate for different cycle lengths, we converted times through a cycle into cycle phase. Values for muscle length were calculated at equal intervals representing $2 \%$ of the total cycle duration. The expected muscle length at each of these points was estimated using the muscle lengths calculated from the joint angles captured from high-speed video recordings. Since the video frames did not occur at $2 \%$ intervals throughout the cycle, it was necessary to estimate the expected muscle length at each of the time points. This was performed by linear interpolation between measured values (from video recordings) at times bracketing the desired point. All muscle lengths were expressed as fractions of the muscle's reference length. The mean length trajectory determined in this way was obviously non-sinusoidal, with a longer shortening phase ( $60 \%$ of the cycle) than lengthening phase in both meso- and metathoracic muscles (Fig. 4; Table 2). The total strain through a cycle was greater in metathoracic muscles (mean 16.4\%) than in mesothoracic ones $(12.0 \%$; Table 2$)$.

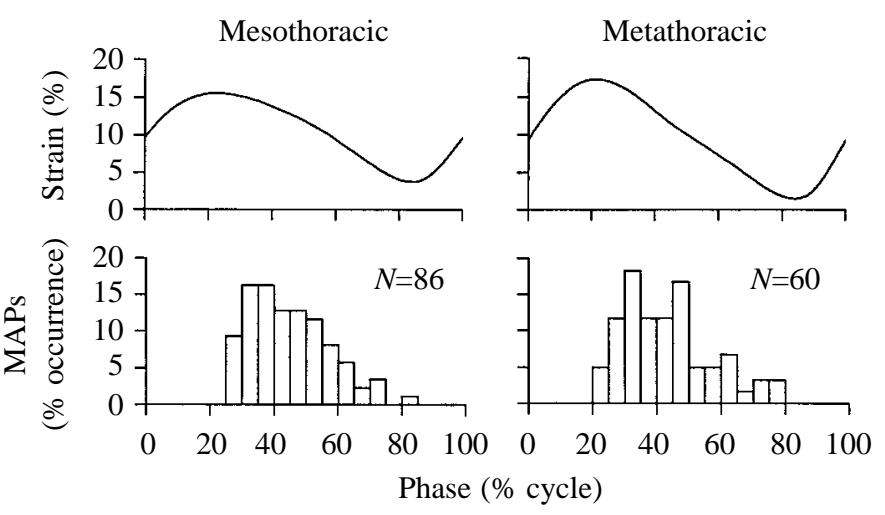

Fig. 4. The average strain trajectory (\% strain) during running cycles from mesothoracic and metathoracic muscles, and the distributions of muscle action potentials (MAPs) in the strain cycles. $N$ is the total number of MAPs.

\section{Muscle action potentials}

There were between one and seven muscle action potentials per cycle in meso- and metathoracic muscles (Fig. 3). The mean number of MAPs per cycle was $3.9 \pm 1.6$ (mean \pm S.D.) for mesothoracic muscles and $2.9 \pm 1.9$ for metathoracic ones. There was a positive correlation between the number of MAPs per cycle and cycle duration in both meso- and metathoracic muscles (Fig. 5; Spearman rank correlation; metathoracic leg, $\rho=0.47, P=0.030$; mesothoracic leg, $\rho=0.68, P=0.002$ ). The mean MAP interval was $10.9 \pm 3.9 \mathrm{~ms}$ (mean \pm S.D.) in mesothoracic muscles and $11.4 \pm 5.8 \mathrm{~ms}$ in metathoracic ones. Successive MAP intervals through a burst were of reasonably constant duration, except that the last intervals were sometimes substantially longer than preceding intervals (Fig. 6).

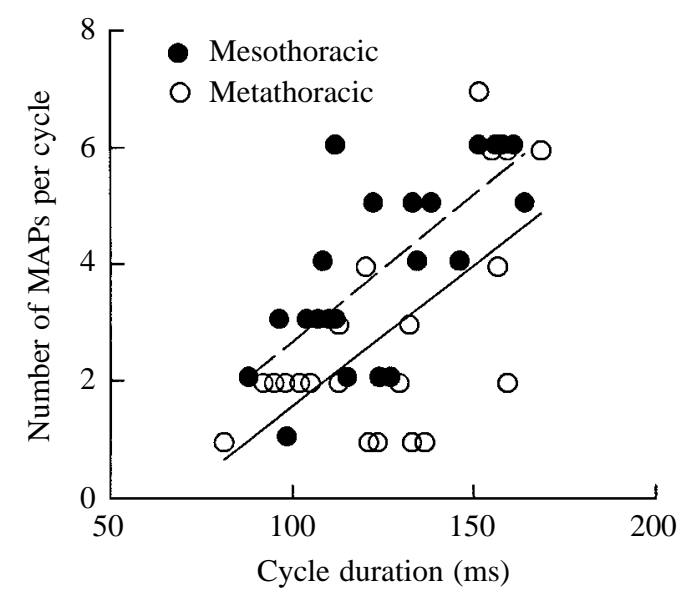

Fig. 5. The relationship between the duration of a stride cycle and the number of muscle action potentials (MAPs) per cycle in the set of cycles analyzed in detail in this study. Values from mesothoracic muscles (dashed line) have been raised slightly on the abscissa, and those from metathoracic muscles (solid line) lowered, in order to reduce overlap between symbols. Regression equations: mesothoracic, MAPs $=0.051 t_{\text {cyc }}-2.5, \quad r^{2}=0.52$; metathoracic, MAPs $=0.048 t_{\text {cyc }}-3.2$; $r^{2}=0.42$, where $t_{\text {cyc }}=$ cycle duration in ms. 


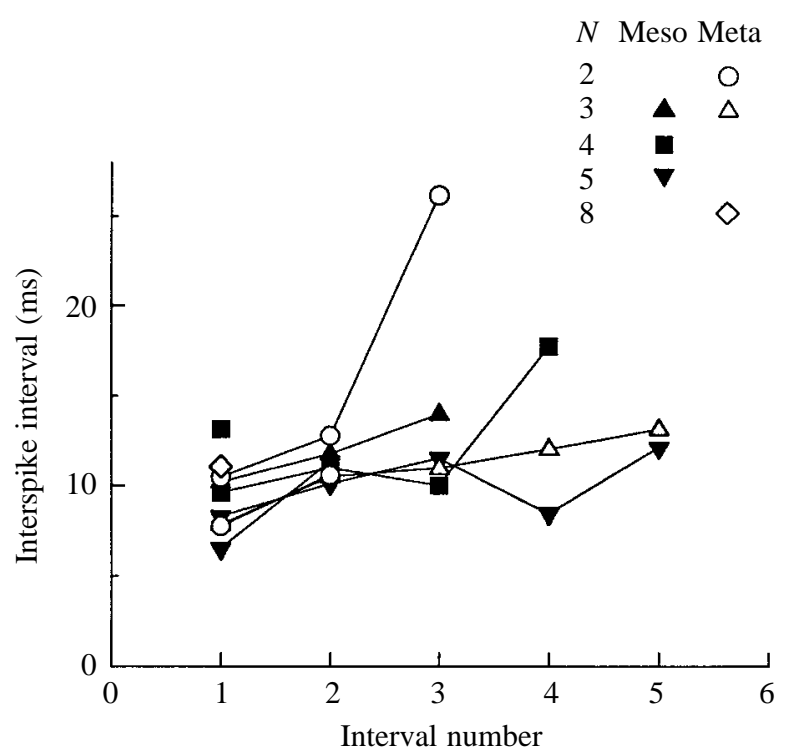

Fig. 6. Intervals between action potentials in the running cycles. In one cycle from a mesothoracic (Meso) muscle and in five from metathoracic (Meta) muscles, there was only a single muscle action potential (MAP) and therefore no interstimulus interval. The values shown are the mean durations for intervals of a burst, plotted as a function of interval number. Lines join symbols from mesothoracic and metathoracic muscles in which the bursts had a common number of interstimulus intervals. The symbols are coded according to the sample size in each set. Note that there was little change in interstimulus interval through a burst, with the exception of two sets in which the terminal MAPs came, on average, after a rather long delay.

MAPs occurred during the shortening phase of the muscle, largely in the first half of shortening (Figs 2, 4). The mean onset time of MAP bursts occurred at a cycle phase of $32.0 \pm 4.4 \%$ (mean \pm S.D.) in mesothoracic muscles and $33.1 \pm 7.6 \%$ in metathoracic muscles.

The features of a 'typical' stride cycle during running, derived from the measurements of muscle strain and activation pattern, are summarized in Table 3.

\section{Muscle contractile properties and work output}

\section{Isometric contractions}

Isometric contraction kinetics were measured in six

Table 3. Characteristics of a typical stride cycle used in work loop experiments

\begin{tabular}{lcc}
\hline & Mesothoracic & Metathoracic \\
\hline Frequency (Hz) & 8 & 8 \\
Mean muscle length (\% RL) & 104.7 & 104.4 \\
Cyclic strain (\% RL) & 12.0 & 16.4 \\
Stimuli per cycle & 4 & 3 \\
Interstimulus interval (ms) & 11 & 11 \\
Stimulus onset, phase in cycle (\%) & 32 & 33 \\
& & \\
RL, reference length (see text). & & \\
\hline
\end{tabular}

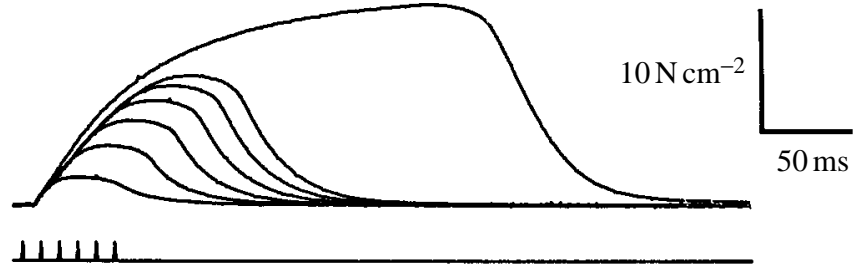

Fig. 7. Isometric contractions of a mesothoracic muscle in response to 1-6 stimuli (bottom trace) at interstimulus intervals of $10 \mathrm{~ms}$ and to a tetanizing burst at an interstimulus interval of $5 \mathrm{~ms}$.

mesothoracic and six metathoracic muscles. Half of the mesothoracic and half of the metathoracic muscles were from males, the other half from females. Three twitches and one tetanic contraction were examined from each preparation. The contractile parameters of the three twitches were averaged to obtain the mean values for each preparation.

Contractile properties were not significantly different in meso- and metathoracic muscles, and in muscles from males and from females (Table 4). Twitch durations, measured from onset to $50 \%$ relaxation $\left(25^{\circ} \mathrm{C}\right)$, were approximately $60 \mathrm{~ms}$, which is approximately half the duration of a single stride. Twitch tension was only approximately $20 \%$ of the maximum tetanic tension (Fig. 7; Table 4).

\section{Work output using sinusoidal strain}

The relationships between the number of stimuli per cycle and the optimal conditions for maximizing work per cycle were nearly identical in meso- and metathoracic muscles (compare Figs 8 and 9). The number of stimuli had a significant effect

Muscle 137 (mesothoracic)
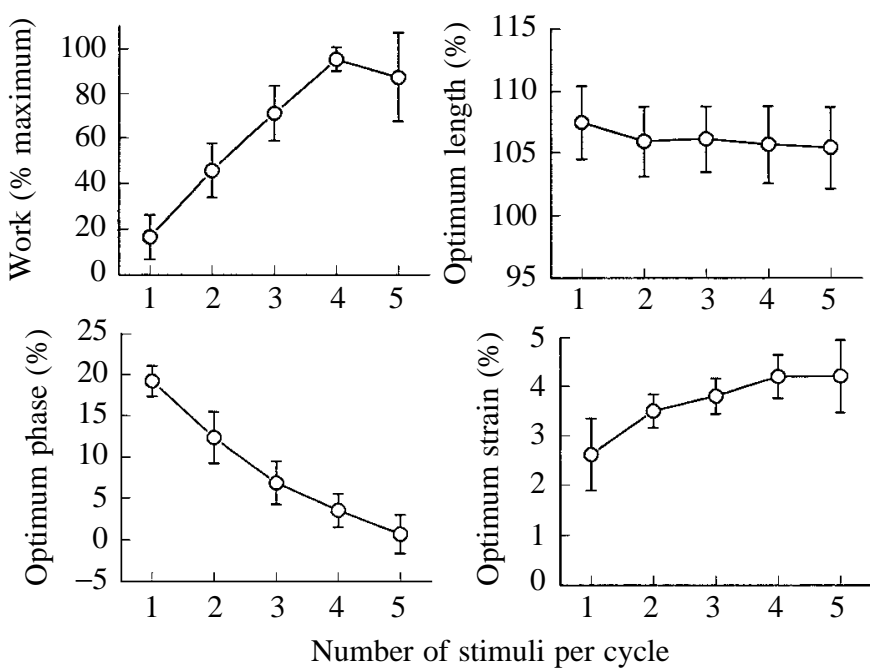

Fig. 8. Relative work output, optimum muscle length, optimum stimulus phase and optimum strain as functions of the number of stimuli per cycle for mesothoracic muscles $(N=6)$ subjected to sinusoidal strain at $8 \mathrm{~Hz}$ and stimulated with bursts of stimuli at an interstimulus interval of $10 \mathrm{~ms}$. Vertical bars indicate \pm S.E.M. 
Table 4. Isometric contractions in trochanter-femoral extensor muscles of Blaberus discoidalis

\begin{tabular}{|c|c|c|c|c|c|}
\hline & \multicolumn{3}{|c|}{ Twitch } & \multirow[b]{2}{*}{$\begin{array}{l}\text { Tetanic tension } \\
\quad\left(\mathrm{N} \mathrm{cm}^{-2}\right)\end{array}$} & \multirow[b]{2}{*}{$\begin{array}{c}\text { Twitch tension/ } \\
\text { tetanic tension } \\
(\%)\end{array}$} \\
\hline & $\begin{array}{l}\text { Rise time } \\
\quad(\mathrm{ms})\end{array}$ & $\begin{array}{l}\text { Onset to } 50 \% \\
\text { relaxation } \\
(\mathrm{ms})\end{array}$ & $\begin{array}{l}\text { Onset to } 90 \% \\
\text { relaxation } \\
\quad(\mathrm{ms})\end{array}$ & & \\
\hline All $(N=12)$ & $27.6 \pm 3.5$ & $61.5 \pm 8.5$ & $126.4 \pm 48.1$ & $17.4 \pm 3.4$ & $20.3 \pm 6.7$ \\
\hline \multicolumn{6}{|l|}{ Sex } \\
\hline Males $(N=6)$ & $27.0 \pm 3.5$ & $61.9 \pm 7.3$ & $132.8 \pm 57.2$ & $15.6 \pm 1.6$ & $20.0 \pm 8.6$ \\
\hline Females $(N=6)$ & $28.3 \pm 3.7$ & $61.2 \pm 10.3$ & $120.0 \pm 41.6$ & $19.2 \pm 3.7$ & $20.6 \pm 4.8$ \\
\hline \multicolumn{6}{|l|}{ Leg } \\
\hline Mesothoracic $(N=6)$ & $27.0 \pm 3.0$ & $61.4 \pm 9.1$ & $122.1 \pm 37.5$ & $19.1 \pm 2.7$ & $17.0 \pm 3.2$ \\
\hline Metathoracic $(N=6)$ & $28.3 \pm 4.2$ & $61.6 \pm 8.7$ & $130.7 \pm 60.4$ & $15.7 \pm 3.2$ & $23.5 \pm 7.9$ \\
\hline
\end{tabular}

Values are given as mean \pm S.D.

on maximal work per cycle (Kruskal-Wallis; metathoracic leg, corrected $H=22.5$, d.f. $=4, \quad P<0.001$; mesothoracic leg, corrected $H=23.4$, d.f. $=4, P<0.001)$. The work per cycle was maximal at four stimuli per cycle and declined with either an increase or a decrease in the number of stimuli per cycle from this number. The optimum stimulus phase declined substantially with increasing number of stimuli per cycle (Kruskal-Wallis; metathoracic leg, corrected $H=24.3$, d.f. $=4$, $P<0.001$; mesothoracic leg, corrected $H=24.9$, d.f. $=4$, $P<0.001)$, whereas the optimal strain increased (Kruskal-Wallis; metathoracic leg, corrected $H=12.0$, d.f. $=4$, $P=0.018$; mesothoracic leg, corrected $H=12.4$, d.f. $=4$, $P=0.014)$. The optimal length declined slightly, but not significantly (Kruskal-Wallis; metathoracic leg, corrected $H=2.45$, d.f. $=4, P=0.66$; mesothoracic leg, corrected $H=0.49$,

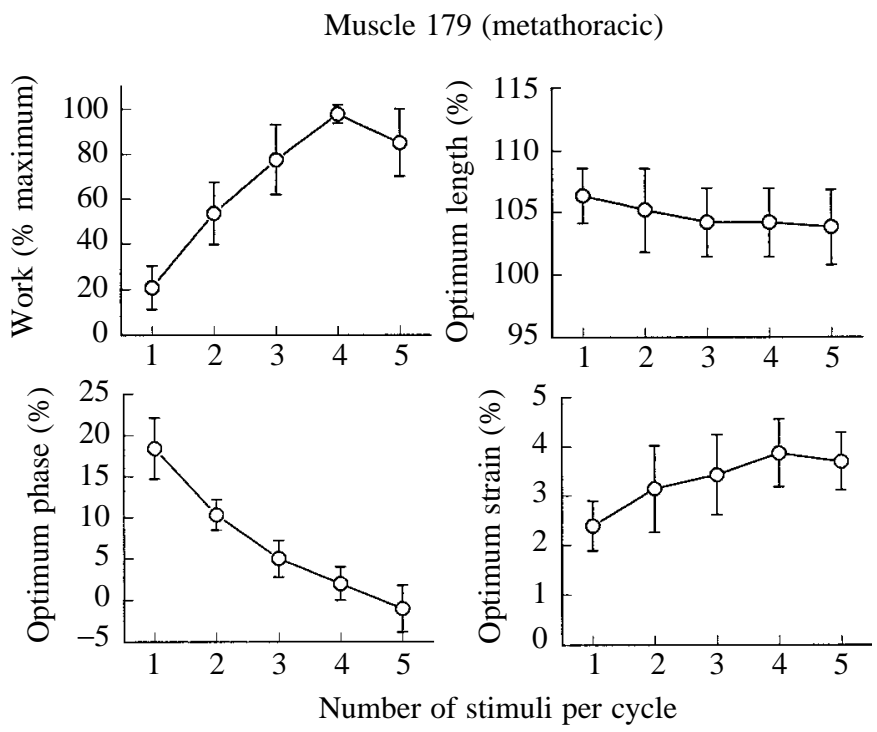

Fig. 9. Relative work output, optimum muscle length, optimum stimulus phase and optimum strain as functions of the number of stimuli per cycle for metathoracic muscles $(N=6)$ subjected to sinusoidal strain at $8 \mathrm{~Hz}$ and stimulated with bursts of stimuli at an interstimulus interval of $10 \mathrm{~ms}$. Vertical bars indicate \pm S.E.M. d.f. $=4, P=0.97)$. The optimal number of stimuli per cycle was similar to the number of action potentials stimulating mesothoracic muscles during running (approximately four nerve impulses and resulting muscle action potentials per cycle; Table 3) and somewhat more than the mean number of action potentials stimulating metathoracic muscles per cycle (approximately three; Table 3 ). The optimal muscle length at maximal work output (105.7\% for the mesothoracic muscles, $104.2 \%$ for the metathoracic counterparts) was similar to the mean muscle length during running. In contrast, the optimal phase at four stimuli per cycle $(3.5 \%$ and $1.3 \%$ for the mesothoracic and metathoracic muscles, respectively) was approximately $30 \%$ less than, or more than a quarter of a cycle earlier than, the actual activation phase during running. The optimal strains for meso- and metathoracic muscles $(4.2 \%$ and $3.9 \%$, respectively) were also quite different from those actually experienced by the muscles while running (12.0\% and $16.4 \%$; Table 3).

The maximal power outputs for meso- and metathoracic muscles given in Table 5 were not significantly different $(P>0.1$, two-tailed $t$-test). The mesothoracic and metathoracic results presented in Table 5 were obtained from different groups of animals. In initial experiments with metathoracic muscles, performed with the same group of animals as those giving the mesothoracic results in Table 5, the maximum power was even more similar in mesothoracic and metathoracic muscles (the metathoracic maximum power was $19.5 \pm 10.2 \mathrm{~W} \mathrm{~kg}^{-1}$, mean \pm S.D., $N=6$ ). An experimental error

Table 5. Work output of mesothoracic and metathoracic trochanter-femoral extensor muscles of Blaberus discoidalis

\begin{tabular}{lcc}
\hline & $\begin{array}{c}\text { Maximum power, } \\
\text { sinusoidal strains } \\
\left(\mathrm{W} \mathrm{kg}^{-1}\right)\end{array}$ & $\begin{array}{c}\text { Power during } \\
\text { simulated running } \\
\left(\mathrm{W} \mathrm{kg}^{-1}\right)\end{array}$ \\
\hline Mesothoracic $(N=6)$ & $19.0 \pm 5.8$ & $-23.7 \pm 7.9$ \\
Metathoracic $(N=6)$ & $29.0 \pm 13.2$ & $-25.4 \pm 22.9$ \\
& & \\
Values are given as mean \pm S.D.
\end{tabular}


A

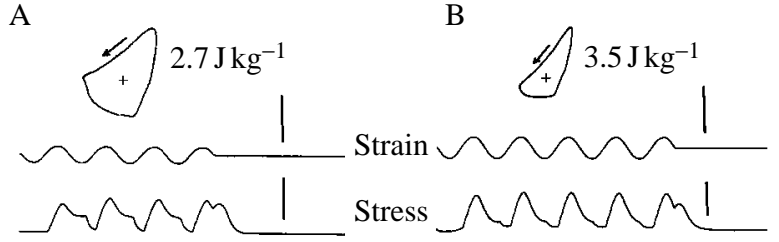

Mesothoracic

$\mathrm{C}$
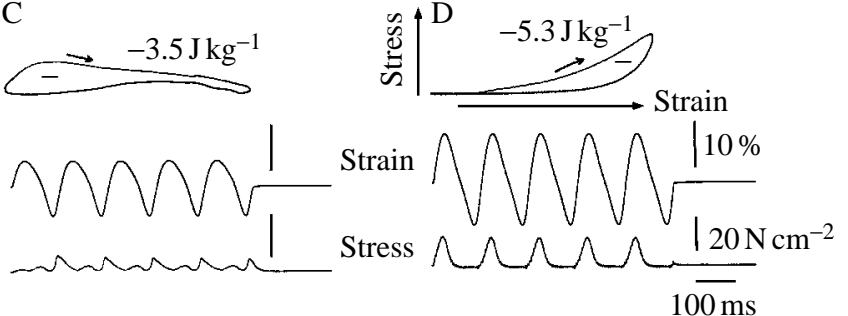

Fig. 10. Muscle force and work loops from a mesothoracic and a metathoracic muscle (muscle mass 1.56 and $2.81 \mathrm{mg}$, respectively). $\mathrm{A}$ and $\mathrm{B}$ are from muscles subjected to sinusoidal strain and the conditions found optimal for work output at $8 \mathrm{~Hz}$ and with interstimulus intervals within bursts of $11 \mathrm{~ms}$ (mesothoracic muscle: strain $4.2 \%$ of reference length, mean muscle length $106 \%$ of reference length, four stimuli per cycle at $11 \mathrm{~ms}$, stimulus phase $3.5 \%$; metathoracic muscle: strain $3.8 \%$, length $104 \%$, four stimuli per cycle at a phase of $1.3 \%$ ). C and D are from muscles subjected to the strain trajectory and activation conditions that pertained during running (strain trajectories those of Fig. 4; stimulus conditions given in Table 3). The upper continuous trace in each panel is muscle strain $(\%)$, the lower continuous trace is stress $\left(\mathrm{N} \mathrm{cm}^{-2}\right)$. Arrows indicate the direction of the work loop.

marred the determination of work from metathoracic muscles during simulated running in the initial series, so it was later repeated with a different group of animals. A slightly higher value resulted for maximum work output. The mean power for the first and second groups taken together was $24.3 \mathrm{~W} \mathrm{~kg}^{-1}$. Thus, the maximum power output of the cockroach leg muscles is of the order of $19-25 \mathrm{~W} \mathrm{~kg}^{-1}$ at $25^{\circ} \mathrm{C}$, with no obvious difference between meso- and metathoracic muscles.

\section{Work during running}

The principle difference between the work loops obtained from muscles operating under conditions that maximized work output and those from the muscles under conditions that simulated running was that the former were entirely counterclockwise and the latter were mostly clockwise (Fig. 10). A clockwise work loop indicates that muscle force is higher during lengthening than during shortening. Therefore, more work is required to extend the muscle than is generated by it during shortening, and work is absorbed rather than produced over a cycle. In only one of the 12 muscles of Table 5 was the net work output positive during loops simulating running, and here (a metathoracic muscle) the net positive work was very small $\left(0.44 \mathrm{~J} \mathrm{~kg}^{-1} \mathrm{cycle}^{-1}=3.5 \mathrm{~W} \mathrm{~kg}^{-1}\right)$. In most preparations, the power associated with simulated running was large and negative (Table 5). Work loops from simulated running were also more complex in shape, and more variable from preparation to preparation, than were those obtained under conditions maximizing work output (Fig. 10). In some preparations, during simulated running, the main clockwise loop was flanked by a small, counterclockwise loop at the long length end, or the short length end, or at both ends.

\section{Dynamic simulation of work during running}

Simulations showed a very narrow parameter space for power production (Fig. 11). The parameter space included power production which corresponded with the measured values from work loop experiments, despite the fact that the simulation used the actual strain pattern rather than the sinusoidal pattern employed to determine maximum power output in the actual muscle (Fig. 11B). The simulation predicted energy absorption for the conditions of the actual muscle during running (three MAPs, phase $33 \%$, strain amplitude $16 \%$; Fig. 11C). With increasing strain, and with movement of phase away from mid-lengthening, the magnitude of energy absorption increased with the number of muscle action potentials per cycle. The absolute values of the simulation output tended to underestimate the power output and to overestimate energy absorption. We suspect that improved parameter estimates (e.g. activation pattern and maximum contraction velocity) together with a consideration of time-dependent effects (e.g. shortening deactivation, stretch activation) could increase the accuracy of the simulation.

\section{Discussion}

The major leg muscles of the cockroach only absorb energy during constant, average-speed running at the animal's preferred speed, despite the fact that these muscles are quite capable of generating power under different conditions and perhaps during other behaviors such as wedging into crevices.

\section{Muscle activation pattern during running - indications of alternative function}

In the present study on the cockroach Blaberus discoidalis, EMG activity was monitored at the animal's preferred speed in trochanter-femoral extensor muscles (137 and 179; Figs 2, 3 ). The preferred speed is approximately one-third of the maximum speed of $60 \mathrm{~cm} \mathrm{~s}^{-1}$ (Full and Tu, 1990). Surprisingly, the number of muscle action potentials (MAPs) actually decreased as cycle or stride frequency increased (Fig. 5), with only minor changes in the interstimulus interval (Fig. 6). A decrease in activity with an increase in speed is unexpected. The comparable trochanter-femoral extensor muscles of the smaller, faster American cockroach Periplaneta americana are both innervated by a single, fast motor axon, $\mathrm{D}_{\mathrm{f}}$, that exits nerve $5 \mathrm{r} 1$ in the mesothoracic ganglion and innervates muscles 137/136 (Becht, 1959; Pearson and Iles, 1971; Pipa and Cook, 1959). A homologous fast axon from the metathoracic ganglion innervates 179/178. Pearson (1972) showed that the fast motor axon $\mathrm{D}_{\mathrm{f}}$ is active only during fast walking and 

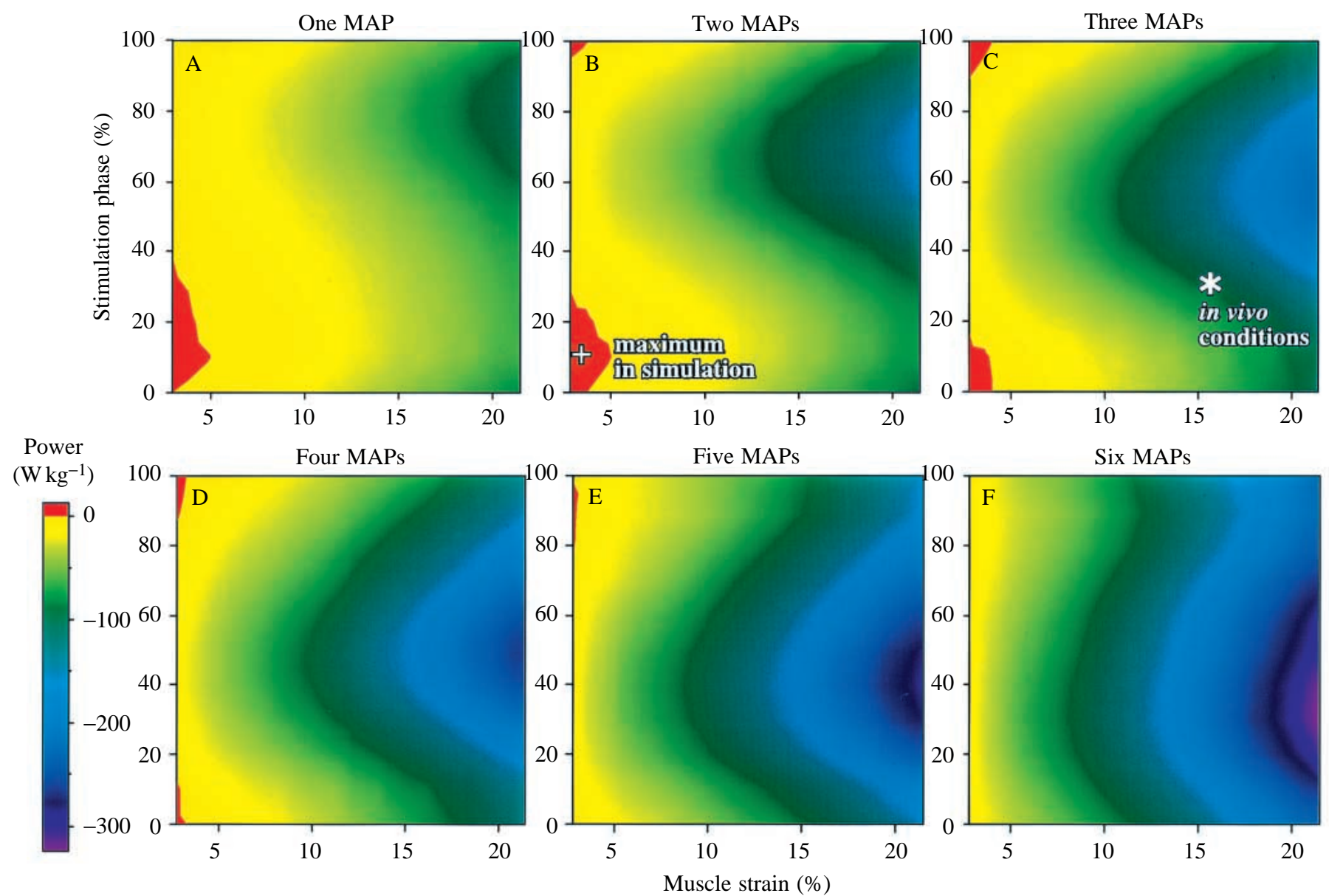

Fig. 11. Power space for muscle 179. The color plots show power generation or absorption calculated for the entire parameter space of muscle strain, stimulation phase and number of stimuli using a dynamic computer model. The actual running kinematics $\left(\right.$ speed $20 \mathrm{~cm} \mathrm{~s}{ }^{-1} ; 8 \mathrm{~Hz}$ stride frequency) were entered into the three-dimensional musculoskeletal model to generate muscle strain. The amplitude of joint angles was adjusted to vary the magnitude of muscle strain. Stimulation phases 0 and 100 represent mid-lengthening. A, B, C, D, E and F show power generation or absorption by muscle 179 with one, two, three, four, five and six muscle action potentials (MAPs) per cycle, respectively. Red areas represent the parameter area for power production. The border between red and yellow represents the conditions during which the muscle behaves as a spring with little net power production or absorption. All other colors represent the parameter space where the muscle absorbs energy. The asterisk represents the conditions used by the animal in vivo during preferred-speed running (three MAPs; $33 \%$ phase; $16 \%$ strain). The plus sign represents the conditions that generated maximum power output in simulation (two MAPs; $10 \%$ phase; $3.5 \%$ strain). These conditions are very similar to the conditions that generated maximum power output in the isolated muscle experiments using a sinusoidal strain pattern (four MAPs; $1.3 \%$ phase; $3.8 \%$ strain).

escape in the American cockroach. Therefore, we anticipated that, in Blaberus discoidalis, power-generating extensor muscles innervated by a fast axon would at least maintain their activity at high speeds. A reduction in burst duration by decreasing the interstimulus interval would not be unexpected because stimulation duty cycle could then remain constant as cycle duration decreased with speed. However, a reduction in the number of MAPs from four to one would probably lead to a decrease in force production (Fig. 7). Yet, ground reaction forces do not decrease with speed or frequency (Full and Tu, 1990). Interestingly, the function of the trochanter-femoral extensor muscles does not appear to be resolved even in the American cockroach, since Delcomyn and Usherwood (1973) could not detect any activity in $\mathrm{D}_{\mathrm{f}}$ during rapid walking.
Activation of muscles 137 and 179 during running occurred just after the beginning of extension and the stance phase (near $30 \%$ phase; Figs 2, 4). MAPs were recorded well into the stance phase. Although no data are available from the American cockroach on the phase of $\mathrm{D}_{\mathrm{f}}$ firing, activity for $\mathrm{D}_{\mathrm{s}}$, the slow motor axon, begins just before extension (Delcomyn and Usherwood, 1973). Power-generating muscles used in terrestrial locomotion are often activated during the swing phase, before touchdown (Goslow et al. 1981; Gregor et al. 1988; Nicolopoulos-Stournaras and Iles, 1984; Prilutsky et al. $1996 a, b$; Roberts et al. 1997) for at least two reasons. First, mechanical events lag behind EMGs, and the extent of lag depends on the rate of muscle force development and the elasticity of the musculo-tendon complex. A muscle must be 
activated before the onset of shortening if it is to produce substantial work during early shortening. Second, active stretch may play an important role in the storage of elastic strain energy (Altringham and Johnston, 1990; Cavagna, 1977; Edman et al. 1978; Komi, 1984). Early activation increases muscle stiffness and facilitates storage of strain energy in tendons and cuticle. Maximum power output of the extensor muscles in the present study was attained with activation beginning during muscle lengthening both in vitro (Figs 8, 9; phases near $5 \%$ ) and in simulation (Fig. 11).

Little or no activity was observed in muscle 87 , which is the prothoracic leg muscle homolog to muscles 137 and 179 of the meso- and metathoracic segments (Fig. 3). Full et al. (1991) showed that the prothoracic leg functions to slow the body down during a step. Perhaps some of the force can be produced by a passive, strut-like function (Hughes, 1951) rather than by active muscles. When Blaberus discoidalis runs at its fastest speeds, we predict that the prothoracic legs may play an even smaller role. The American cockroach runs on only four or two legs at high speeds without touching down on the prothoracic legs at all (Full and Koehl, 1993; Full and Tu, 1991).

The reduction of activation with speed, the late phase of activation and the lack of activation in the prothoracic legs indicate that the anterior trochanter-femoral extensor muscles of Blaberus discoidalis are not the major power generators during running.

\section{Muscle contractile properties - a role in control?}

The contractile properties of the anterior trochanter-femoral extensor muscles in Blaberus discoidalis point to a possible role in the control of leg movement. The twitch/tetanus tension ratio in Blaberus discoidalis was rather low, approximately 0.2 (Table 4; Fig. 7). For comparison, the equivalent mesothoracic muscle in the faster-running American cockroach Periplaneta americana has a twitch/tetanus ratio of 0.67-0.83 (Usherwood, 1962; Becht and Dresden, 1956). The twitch/tetanus ratio of a tergocoxal muscle, a muscle that is both a leg muscle and a flight muscle, from the locust Schistocerca gregaria is approximately 0.6 (Malamud et al. 1988). The low twitch/tension ratio in the extensor muscle of $B$. discoidalis indicates the potential for greater control of force. Varying the stimulation pattern (i.e. the number of muscle action potentials or the interstimulus interval) allows a finer gradation in force development than would be true were the twitch/tetanus ratio higher. Although their twitch tension is relatively low, the maximum isometric stress of Blaberus discoidalis muscles $137 / 179$ (17.4 $\mathrm{N} \mathrm{cm}^{-2}$; Table 4) falls well within the wide range reported for invertebrate and vertebrate muscles (2-80 $\mathrm{N} \mathrm{cm}^{-2}$; mean 24 $\mathrm{N} \mathrm{cm}^{-2}$; Full, 1997; Josephson, 1993).

Blaberus discoidalis is a slower runner than the more familiar American cockroach Periplaneta americana. Our values for the stride frequency during running by $B$. discoidalis (mean $8 \mathrm{~Hz}$, maximum $12 \mathrm{~Hz}$ ) are approximately half those reported for $P$. americana during rapid running (20-25 Hz, Delcomyn, 1971; Full and Tu, 1991). Presumably related to the slower operating frequency, the time course of twitches from the trochanter- femoral extensor muscles of $B$. discoidalis is approximately twice as long as that from equivalent muscles in $P$. americana, and in both species the twitch duration, measured from onset to $50 \%$ relaxation, closely matches the half-cycle duration during rapid running. The twitch rise time in $B$. discoidalis was $28 \mathrm{~ms}$ (Table 4); that in P. americana is $13.5 \mathrm{~ms}$ (Usherwood, 1962). The twitch duration, to $50 \%$ relaxation, was $62 \mathrm{~ms}$ in $B$. discoidalis and the half-cycle duration, at $8 \mathrm{~Hz}$, was $63 \mathrm{~ms}$; the twitch duration in $P$. americana is $23.8 \mathrm{~ms}$ (Usherwood, 1962) and the half-cycle duration is $20-25 \mathrm{~ms}$. In the limb muscles of lizards, as in the leg muscles of cockroaches, there is agreement between the twitch duration of limb muscles and the half-cycle duration during running. In the lizards Dipsosaurus dorsalis and Sceloporus occidentalis, the twitch duration, from onset to $50 \%$ relaxation, of muscles used in running is nearly the same as the half-cycle duration during sprinting at temperatures up to $25^{\circ} \mathrm{C}$ (Marsh and Bennett, 1986; Marsh, 1990; Johnson et al. 1993). However, there is divergence, with the twitch duration becoming relatively shorter, between twitch duration and halfcycle duration at higher temperatures. The point to be made is that a twitch from a cockroach extensor muscle (or from a lizard limb muscle) is short enough to fit largely within the shortening half-cycle during locomotion. In fact, shortening deactivation will probably shorten the effective duration of a twitch during running relative to the isometric twitch duration and the halfcycle duration (Josephson and Stokes, 1989; Rome and Swank, 1992). The work from the cockroach muscles during running is negative not because of the inescapable limitations in muscle kinetics, but because the muscles are activated multiply in each cycle rather than once, as in a twitch, and because of the large strain experienced by the muscles.

\section{Extensor muscles as capable power generators - work output using sinusoidal strain}

Trochanter-femoral extensor muscles 137 and 179 of the cockroach Blaberus discoidalis were capable actuators able to generate a power of $19-25 \mathrm{~W} \mathrm{~kg}^{-1}$ (Table 5). It is important to note that this range of power output is in no way unusual. The maximum power output of the cockroach extensor muscles is equivalent to that from several vertebrate and invertebrate skeletal muscles measured at similar temperatures $\left(28 \mathrm{~W} \mathrm{~kg}^{-1}\right.$ for fish myotomal muscles at $20^{\circ} \mathrm{C}$, Rome and Swank, 1992; $35 \mathrm{~W} \mathrm{~kg}^{-1}$ for frog sartorius muscle and $29 \mathrm{~W} \mathrm{~kg}^{-1}$ for toad sartorius muscle at $20^{\circ} \mathrm{C}$, Stevens, 1988,$1993 ; 27 \mathrm{~W} \mathrm{~kg}^{-1}$ for rat diaphragm muscle at $29^{\circ} \mathrm{C}$, Stevens and Syme, 1989; $35 \mathrm{~W} \mathrm{~kg}^{-1}$ for moth flight muscle at $25^{\circ} \mathrm{C}$, Stevenson and Josephson, 1990).

As expected from the low twitch/tetanus ratio, the number of stimuli per cycle had a considerable effect on force development and therefore power output in Blaberus discoidalis extensor muscles. Increasing the number of stimuli per cycle from one to four increased power output by fivefold (Figs 8, 9). The greatest power outputs occurred with four MAPs per burst. Five stimuli per cycle did not increase power output because the increased force during shortening is compromised by greater energy loss during relengthening. 
The optimum phase of stimulation onset in Blaberus discoidalis trochanter-femoral extensor muscles occurred from midway through lengthening to near the beginning of muscle shortening, depending on the duration of stimulation. The optimum phase decreased with increasing stimulus duration (Figs 8, 9). To attain maximum power, muscles had to be stimulated earlier in the lengthening phase (from $20 \%$ to $0 \%$ phase) as force production was increased by increasing the number of stimuli per cycle. A similar shift is found in the simulated data (Fig. 11 going from A to C). These data confirm the extremely problematic nature of attempting to predict muscle function from EMG activity alone. In the American cockroach, Delcomyn and Usherwood (1973) showed that, at the highest speeds of locomotion, the electrical activity of the slow extensor motor axon $\mathrm{D}_{\mathrm{s}}$ began before the leg was halfway through flexion. They concluded that at high speeds of leg movement much of the energy output of the muscle would seem to be expended in overcoming inertia in reversing the direction of the leg movement. Although this may be true in the American cockroach with faster twitch muscle, the same reasoning applied to Blaberus discoidalis would result in an erroneous conclusion because of its slower muscles. In fact, activating Blaberus discoidalis trochanter-femoral extensor muscles $137 / 179$ midway through lengthening is required to generate the greatest power, not to absorb energy.

The strain of muscles 137/179 that resulted in the greatest power production was approximately $4 \%$ both in vitro (Figs 8 , 9) and in simulation (Fig. 11). Optimal strain increased with the number of stimuli per cycle, but the magnitude of the change was small. An optimum strain amplitude of approximately $4-5 \%$ is relatively low, but not unusual at this operating frequency. It is similar to that of the flagellum abductor muscle in a crab $(5.7 \%$ at $10 \mathrm{~Hz}$; Josephson and Stokes, 1994) and the wing elevator of a katydid (5.5\% at $25 \mathrm{~Hz}$; Josephson, 1985), greater than that measured in most insect asynchronous flight muscles (<1-3\%; Josephson, 1997; Gilmour and Ellington, 1993; Chan and Dickinson, 1996), but less than that of many other skeletal muscles (approximately $10 \%$; Stevens, 1988; Stokes and Josephson, 1988; Josephson and Stokes, 1989; Syme and Stevens, 1989; Altringham and Johnston, 1990; Altringham and Young, 1991; James et al. 1995). A $4 \%$ amplitude of strain in Blaberus discoidalis corresponds to a joint angle change of approximately $12^{\circ}$ (Fig. 1). Joint angles of the coxa-trochanter-femur joint during preferred-speed running average 3-4 times the change necessary for the greatest power output (angles for mesothoracic legs $43.5-86.5^{\circ}$; range $43.0^{\circ}$; and for metathoracic legs $35.7-105.9^{\circ}$; range $70.2^{\circ}$; Kram et al. 1997; Fig. 1). Data from the present study demonstrate that strains required for the maximum power output by the trochanterfemoral extensor muscles 137/179 simply do not occur during constant, average-speed running.

\section{Extensor muscles as active dampers for control - work during simulated running}

Clearly, trochanter-femoral extensor muscles (137 and 179) in the running animal do not operate under conditions which maximize power output or efficiency. At the preferred running speed of Blaberus discoidalis of $20 \mathrm{~cm} \mathrm{~s}^{-1}$ (frequency $8 \mathrm{~Hz}$ ), these muscles absorb energy at a rate of approximately $25 \mathrm{~W} \mathrm{~kg}^{-1}$ (Fig. 10, Table 5). What is not clear is how wide a range of parameters results in energy absorption and where the transitions between absorption and production lie in the complex, multi-dimensional parameter space which includes muscle strain, stimulus phase and stimulus pattern. These are difficult questions to answer with physiological measurements. Many data points are needed to chart the parameter space adequately. The performance of the muscle preparations declines with time and intensity of testing, which limits the number of data points obtained from a single muscle. As a means to bypass the limitations imposed by the fragility of the muscle preparations, we used a dynamic computer simulation from a three-dimensional musculo-skeletal model (Full and Ahn, 1995) to explore the parameter space more broadly.

Dynamic simulation of the muscle's capacity reveals a consistent pattern illustrating the dependence of energy production and absorption on stimulus pattern, stimulus phase and strain (Fig. 11). It is obvious from the simulation that the production of net positive work from muscle 179 is only possible in a small part of the parameter space. Power production (red areas in Fig. 11) primarily results when the number of stimuli is less than four, stimulus phase ranges from the beginning of muscle lengthening until shortly after the onset of shortening (90-100\% and 0-20\%) and strain is less than $5 \%$. These are very near the conditions we discovered for maximal power output using the actual muscle even when we employed simple, sinusoidal strain patterns (Figs 8, 9, 11B).

Trochanter-femoral extensor muscles are more likely to absorb energy than to produce it within the relevant parameter space in which we found they operate (all non-red areas in Fig. 11). Large parameter spaces showing energy absorption (negative work) have been measured in fish myotomal muscle when phase is varied (James et al. 1996; Johnson and Johnston, 1991). In the cockroach Blaberus discoidalis, a greater number of stimuli, phases shifted away from mid-lengthening, and larger strains favor energy absorption (Fig. 11). Even though particular ranges of each of these parameters can favor energy absorption, the dominant parameter that determines function during running appears to be the magnitude of strain. No pattern of stimulation or phase can result in power production if the magnitude of strain is greater than $5 \%$. Strain must be greater than $5 \%$ if stride length is to be adequate at the animal's preferred speed. Stride length sets the joint angles through which the legs must move, thus determining strain. Dynamic coupling of segment mechanics prevents large adjustments in stride length, joint angles and strains at a given speed, whereas we imagine that alterations in stimulus phase and in stimulus pattern could be made more easily. The simulation predicts that increases in strain should result in greater energy absorption (Fig. 11). Tu and Dickinson (1994) measured such a relationship for blowfly steering muscle.

All else being equal, an increase in strain (=shortening 
distance) could result in an increase in positive work. However, an increase in strain without a concomitant decrease in cycle frequency increases strain rate. An increase in contraction velocity results in force reduction during shortening due to a muscle's force-velocity relationship. This same force-velocity function actually results in elevated forces during the relengthening period. Both of these effects, greater forces during lengthening and less force during shortening, are apparent in our simulation and result in substantial amounts of energy absorption.

The expanded view of muscle capacity afforded by simulation (Fig. 11) indicates that we should not be surprised by energy absorption of extensors, but that we should expect it in instances in which there are relatively large strains coupled with typical muscle force kinetics. Our Hill-based simulation does not include all the history-dependent effects on muscle mechanics (see Sandercock and Heckman, 1997), such as shortening-induced inactivation (Ekelund and Edman, 1982; Edman, 1980) or extra tension following an active stretch (Edman et al. 1978, 1982). These time-dependent effects further shape the force trajectory. Shortening deactivation may reduce the work done by a muscle during the later parts of the shortening phase (Fig. 10D). However, as demonstrated in a crustacean muscle (Josephson and Stokes, 1989), shortening deactivation can also reduce the work required to re-extend a muscle after it has shortened and, in this way, increase the net work per cycle. Similarly, it is to be expected that stretch activation can increase the work output early in shortening, but it may also increase the work required to re-extend the muscle and thus may reduce net work over a full cycle. The overall effect of shortening deactivation and stretch activation on power output will depend on the rate constants governing these processes and the frequency components in the muscle length changes.

The advantage or disadvantage of energy absorption by trochanter-femoral extensors remains speculative. Muscle 179 in the metathoracic leg and muscle 137 in the mesothoracic leg may function to control leg flexion and aid in its reversal. Perhaps this function is more important in a sprawled-postured animal that swings its limbs in a more horizontal plane than in birds and mammals with upright stances. In birds and mammals, gravity can assist the return of limbs to the vertical resting position, whereas swinging limbs parallel to the ground may require more active braking and control of position. Evidence that active energy absorption is a design characteristic of these muscles may in all likelihood be difficult to find, particularly if the muscle is serving a dual function. Still, the low twitch/tetanus ratio of these cockroach muscles and the increase in activation at slower running speeds are consistent with a role in control. Many stimuli are required to activate the muscles fully, thus allowing better gradation of muscle force. Finally, the capacity for energy absorption in these muscles appears to be substantial. Muscles 178 and 179 are both innervated by the same axon $\left(\mathrm{D}_{\mathrm{f}}\right)$, and their serial homologs (136 and 137) in the mesothoracic segment are similarly innervated by a common axon. Given their common innervation, it is likely that muscles 178 and 179 have a similar function. Muscles 178 and 179 together constitute $28 \%$ of the total extensor muscle mass in the metathoracic leg. The estimated combined force of these muscles nearly equals the value of the largest extensor muscle (177c; Full and Ahn, 1995). Calculations show that the energy absorbed by these extensors is more than sufficient to bring a leg in the swing phase to a halt at the position of maximum flexion (Kram et al. 1997).

Despite the evidence that trochanter-femoral extensor muscles (137 and 179) are activated by a fast motor axon at the beginning of the stance phase, they do not operate at maximal power output or efficiency during preferred-speed running. These muscles function as active energy absorbers or dampers. In addition to being power generators, muscles have been shown to be part of active springs (Alexander, 1988; Roberts et al. 1997; Biewener and Baudinette, 1995) and both to produce and to absorb energy over a cycle, possibly allowing energy transfer (Prilutsky et al. 1996a,b). However, we are unable to find conclusive evidence pointing to another muscle used solely as an active energy absorber during terrestrial locomotion. Perhaps the only muscle discovered thus far with a similar role is the steering muscle of the blowfly which, at wingbeat frequencies, can only absorb energy and functions in the control of aerodynamic yaw torque during flight (Tu and Dickinson, 1994). We agree with Daniel (1995) when he stated that 'The idea that some energy dissipation is needed for dynamic stability has not been examined in detail for any locomotor system and deserves additional attention'.

We would like to thank G. Lauder for his technical assistance and for the use of equipment. This research was supported by NSF Grant PYI DCB 90-58138 to R.J.F., NSF Grants IBN-9104170 and IBN-9603187 to R.K.J. and an ONR Grant NOOO14-92-J-1250 ASSERT Award to A.N.A.

\section{References}

AleXANDER, R. McN. (1988). Elastic Mechanisms in Animal Movement. Cambridge: Cambridge University Press.

ALEXANDER, R. MCN. (1997). Optimum muscle design for oscillatory movements. J. theor. Biol. 184, 253-259.

Altringham, J. D. And Johnston, I. A. (1990). Modelling muscle power output in fish. J. exp. Biol. 148, 395-402.

Altringham, J. D., Wardle, C. S. And Smith, C. I. (1993). Myotomal muscle function at different locations in the body of a swimming fish. J. exp. Biol. 182, 191-206.

Altringham, J. D. And Young, I. S. (1991). Power output and the frequency of oscillatory work in mammalian diaphragm muscle: the effects of animal size. J. exp. Biol. 157, 381-389.

BECHT, G. (1959). Studies on insect muscles. Bijdr. Dierk. 29, 1-40. Becht, G. AND Dresden, D. (1956). Physiology of the locomotory muscles in the cockroach. Nature 177, 836-837.

Becht, G., Hoyle, G. And Usherwood, P. N. R. (1960). Neuromuscular transmission in the coxal muscles of the cockroach. J. Insect Physiol. 4, 191-201.

Biewener, A. A. AND BAudinetTe, R. V. (1995). In vivo muscle force 


\section{Mechanics of muscle in running insects 1011}

and elastic energy storage during steady-speed hopping of Tammar wallabies (Macropus eugenii). J. exp. Biol. 198, 1829-1841.

Blickhan, R. AND Full, R. J. (1993). Similarity in multilegged locomotion: Bouncing like a monopode. J. comp. Physiol. 173, 509-517.

Boettinger, E. G. (1957). The machinery of insect flight. In Recent Advances in Invertebrate Physiology (ed. B. T. Scheer), pp. 117-142. Oregon: University of Oregon Publications.

Carbonell, C. S. (1947). The thoracic muscles of the cockroach Periplaneta americana. Smithson. misc. Collns 107, 1-23.

Cavagna, G. A. (1977). Storage and utilization of elastic energy storage in skeletal muscle. Exerc. Sports Sci. Rev. 5, 89-129.

Cavagna, G. A., Heglund, N. C. and Taylor, C. R. (1977). Mechanical work in terrestrial locomotion: two basic mechanisms for minimizing energy expenditure. Am. J. Physiol. 233, R243-R261.

CHAN, W. P. AND Dickinson, M. H. (1996). In vivo length oscillations of indirect flight muscles of the fruit fly Drosophila virilis. J. exp. Biol. 199, 2767-2774.

DANIEL, T. L. (1995). Invertebrate swimming: Integrating internal and external mechanics. Exp. Biol. XLIX, 61-89.

Delcomyn, F. (1971). The locomotion of the cockroach Periplaneta americana. J. exp. Biol. 54, 443-452.

Delcomyn, F. AND Usherwood, P. N. R. (1973). Motor activity during walking in the cockroach Periplaneta americana. I. Free walking. J. exp. Biol. 59, 629-642.

EDMAN, K. A. P. (1980). Depression of mechanical performance by active shortening during twitch and tetanus of vertebrate muscle fibres. Acta physiol. scand. 109, 15-26.

Edman, K. A. P., Elzinga, G. And Noble, M. I. H. (1978). Enhancement of mechanical performance by stretch during tetanic contractions of vertebrate skeletal muscle fibres. J. Physiol., Lond. 281, 139-155.

Edman, K. A. P., Elzinga, G. AND Noble, M. I. H. (1982). Residual force enhancement after stretch of contracting frog single muscle fibers. J. gen. Physiol. 80, 769-784.

Ekelund, M. C. AND Edman, K. A. P. (1982). Shortening induced deactivation of skinned fibres of frog and mouse striated muscle. Acta physiol. scand. 116, 189-199.

Full, R. J. (1989). Mechanics and energetics of terrestrial locomotion: From bipeds to polypeds. In Energy Transformations in Cells and Animals (ed. W. Wieser and E. Gnaiger), pp. 175-182. Stuttgart: Thieme.

Full, R. J. (1997). Invertebrate locomotor systems. In The Handbook of Comparative Physiology (ed. W. Dantzler), pp. 853-930. New York: Oxford University Press.

Full, R. J. AND AHN, A. N. (1995). Static forces and moments generated in the insect leg: comparison of a three-dimensional musculo-skeletal computer model with experimental measurements. J. exp. Biol. 198, 1285-1298.

Full, R. J., Blickhan, R. AND Ting, L. H. (1991). Leg design in hexapedal runners. J. exp. Biol. 158, 369-390.

Full, R. J. And Koehl, M. A. R. (1993). Drag and lift on running insects. J. exp. Biol. 176, 89-101.

Full, R. J. AND TU, M. S. (1990). Mechanics of six-legged runners. J. exp. Biol. 148, 129-146.

FULL, R. J. AND TU, M. S. (1991). Mechanics of a rapid running insect: two-, four- and six-legged locomotion. J. exp. Biol. 156, 215-231.

Full, R. J., Yamauchi, A. AND Jindrich, D. L. (1995). Single leg force production: cockroaches righting and running on photoelastic gelatin. J. exp. Biol. 198, 2441-2452.
Gilmour, K. M. And Ellington, C. P. (1993). In vivo muscle length changes in bumblebees and the in vitro effects on work and power. J. exp. Biol. 183, 101-113.

Goslow, G. E., Jr, Seeherman, H. J., Taylor, C. R., McCutchin, M. N. AND Heglund, N. C. (1981). Electrical activity and relative length changes of dog limb muscles as a function of speed and gait. J. exp. Biol. 94, 15-42.

Gregor, R. J., Roy, R. R., Whiting, W. C., Lovely, R. G., Hodgson, J. A. AND Edgerton, V. R. (1988). Mechanical output of the cat soleus during treadmill locomotion: in vivo vs in situ characteristics. J. Biomech. 94, 15-42.

HiLl, A. V. (1950). The dimensions of animals and their muscular dynamics. Sci. Prog. 38, 209-230.

Hughes, G. M. (1951). The co-ordination of insect movements. I. The walking movements of insects. J. exp. Biol. 29, 267-283.

James, R. S., Altringham, J. D. And Goldspink, D. F. (1995). Mechanical properties of fast and slow skeletal muscles of the mouse in relation to their locomotory function. J. exp. Biol. 198, 491-502.

James, R. S., Young, I. S., Cox, V. M., Goldspink, D. F. AND Altringham, J. D. (1996). Isometric and isotonic muscle properties as determinants of work loop power output. Pflügers Arch. Eur. J. Physiol. 432, 767-774.

Johnson, T. P. And Johnston, I. A. (1991). Power output of fish muscle fibres performing oscillatory work: effects of acute and seasonal temperature change. J. exp. Biol. 157, 409-423.

Johnson, T. P., Swoap, S. J., Bennett, A. F. And Josephson, R. K. (1993). Body size, muscle power output amd limitations on burst locomotor performance in the lizard Dipsosaurus dorsalis. J. exp. Biol. 174, 199-213.

Johnston, I. A., van Leeuwen, J. L., Davies, M. L. F. And Beddow, T. (1995). How fish power predation fast-starts. J. exp. Biol. 198, 1851-1861.

JosEPHSON, R. K. (1985). Mechanical power output from striated muscle during cyclic contraction. J. exp. Biol. 114, 493-512.

JoSEPHSON, R. K. (1993). Contraction dynamics and power output of skeletal muscle. A. Rev. Physiol. 55, 527-546.

JosEPHSON, R. K. (1997). Power output from a flight muscle of the bumblebee Bombus terrestris. III. Power during simulated flight. $J$. exp. Biol. 200, 1241-1246.

Josephson, R. K. AND StoKes, D. R. (1989). Strain, muscle length and work output in a crab muscle. J. exp. Biol. 145, 45-61.

JoSEPHSON, R. K. AND STOKES, D. R. (1994). Contractile properties of a high-frequency muscle from a crustacean. III. Mechanical power output. J. exp. Biol. 187, 295-303.

KER, R. F. (1977). Some structural and mechanical properties of locust and beetle cuticle. PhD thesis, University of Oxford.

Komi, P. V. (1984). Physiology and biomechanical correlates of muscle function: Effects of muscle structure and stretch-shortening cycle on force and speed. Exerc. Sports Sci. Rev. 12, 81-123.

Kram, R., Wong, B. AND Full, R. J. (1997). Three-dimensional kinematics and limb kinetic energies of running cockroaches. $J$. exp. Biol. 200, 1919-1929.

Layland, J., Young, I. S. And Altringham, J. D. (1995). The effect of cycle frequency on the power output of rat papillary muscles in vitro. J. exp. Biol. 198, 1035-1043.

Lutz, G. J. AND Rome, L. C. (1994). Built for jumping: The design of the frog muscular system. Science 263, 370-372.

Machin, K. E. AND PRINGLE, J. W. S. (1960). The physiology of insect fibrillar muscle. III. The effect of sinusoidal changes of length on a beetle flight muscle. Proc. R. Soc. Lond. B 151, 204-255. 


\section{R. J. FULL AND OTHERS}

Malamud, J. G. AND Josephson, R. K. (1991). Force-velocity relationships of a locust flight muscle at different times during a twitch contraction. J. exp. Biol. 159, 65-87.

Malamud, J. G., Mizisin, A. P. And Josephson, R. K. (1988). The effects of octopamine on contraction kinetics and power output of a locust flight muscle. J. comp. Physiol. A 162, 827-835.

Marsh, R. L. And BennetT, A. F. (1986). Thermal dependence of contractile properties of skeletal muscle from the lizard Sceloporus occidentalis with comments on methods for fitting and comparing force-velocity curves. J. exp. Biol. 126, 63-77.

MARSH, R. L. (1990). Deactivation rate and shortening velocity as determinates of contractile frequency. Am. J. Physiol. 259, R230-R233.

Meyhofer, E. AND DANiel, T. L. (1990). Dynamic mechanical properties of extensor muscle cells of the shrimp Pandalus danae: cell design for escape locomotion. J. exp. Biol. 151, 435-452.

Miller, R. A. (1979). Insect Neurophysiological Techniques. New York: Springer Verlag. 308pp.

Nicolopoulos-Stournaras, S. ANd Iles, J. F. (1984). Hind limb muscle activity in the rat. J. Zool., Lond. 203, 427-440.

Pearson, K. G. (1972). Central programming and reflex control of walking in the cockroach. J. exp. Biol. 56, 173-193.

PeArson, K. G. AND Iles, J. F. (1971). Innervation of coxal depressor muscles in the cockroach Periplaneta americana. J. exp. Biol. 54, 215-232.

PIPA, R. L. AND CoOK, E. F. (1959). Studies on the hexapod nervous system. I. The peripheral distribution of the thoracic nerves of the adult cockroach, Periplaneta americana. Ann. ent. Soc. Am. 52, 695-710.

Prilutsky, B. I., Herzog, W. And Allinger, T. L. (1996a). Mechanical power and work of cat soleus, gastrocnemius and plantaris muscles during locomotion: possible functional significance of muscle design and force patterns. J. exp. Biol. 199, 801-814.

Prilutsky, B. I., Herzog, W. And Leonard, T. (1996b). Transfer of mechanical energy between ankle and knee joints by gastrocnemius and plantaris muscles during cat locomotion. J. Biomech. 29, 391-403.

Roberts, T. J., Marsh, R. L., Weyand, P. G. and Taylor, C. R. (1997). Muscular force in running turkeys: The economy of minimizing work. Scienc. 275, 1113-1115.

Rome, L. C., Funke, R. P., Alexander, R. McN., Lutz, G., Aldridge, H., Scott, F. AND Freadman, M. (1988). Why have different muscle fibre types? Nature 355, 824-827.

Rome, L. C. AND Swank, D. (1992). The influence of temperature on power output of scup red muscle during cyclical length changes. $J$. exp. Biol. 171, 261-281.

Rome, L. C., Swank, D. And CoRda, D. (1993). How fish power swimming. Science 261, 340-343.
Rome, L. C., Syme, D. A., Hollingsworth, S., Lindstedt, S. L. AND BAYLOR, S. (1996). The whistle and the rattle: The design of sound producing muscles. Proc. natn. Acad. Sci. U.S.A. 93, 8095-8100.

SAndercock, T. G. And Heckman, C. J. (1997). Force from cat soleus muscle during imposed locomotor-like movements: Experimental data versus Hill-type model predictions. J. Neurophysiol. 77, 1538-1552.

SteVEns, E. D. (1988). Effect of $\mathrm{pH}$ and stimulus phase on the work done by isolated frog sartorius muscle during cyclic contractions. J. Muscle Res. Cell Motil. 9, 329-333.

STEVENS, E. D. (1993). Relation between work and power calculated from force-velocity curves to that done during oscillatory work. $J$. Muscle Res. Cell Motil. 14, 518-526.

Stevens, E. D. And Syme, D. A. (1989). The relative changes in isometric force and work during fatigue and recovery in isolated toad sartorius muscle. Can. J. Physiol. Pharmac. 67, 1544-1548.

Stevenson, R. D. And Josephson, R. K. (1990). Effects of operating frequency and temperature on mechanical power output from moth flight muscle. J. exp. Biol. 149, 61-78.

StoKes, D. R. AND Josephson, R. K. (1988). The mechanical power output of a crab respiratory muscle. J. exp. Biol. 140, 287-299.

Syme, D. A. (1993). Influence of extent of muscle shortening and heart rate on work from frog heart trabeculae. Am. J. Physiol. 265, R310-R319.

Syme, D. A. And Stevens, E. D. (1989). Effect of cycle frequency and excursion amplitude on work done by rat diaphragm muscle. Can. J. Physiol. Pharmac. 67, 1294-1299.

Tu, M. S. AND DiCKINSON, M. H. (1994). Modulation of negative work output from a steering muscle of the blowfly Calliphora vicina. J. exp. Biol. 192, 207-224.

Usherwood, P. N. R. (1962). The nature of 'slow' and 'fast' contractions in the coxal muscles of the cockroach. J. Insect Physiol. 8, 31-52.

van Leeuwen, J. L., Lankheet, M. J. M., Akster, H. A. And Osse, J. W. M. (1990). Function of red axial muscles of carp (Cyprinus carpio): Recruitment and normalized power output during swimming in different modes. J. Zool., Lond. 220, 123-145.

VIDELER, J. J. AND HeSs, F. (1984). Fast continuous swimming of two pelagic predators, saithe (Pollachius virens) and mackerel (Scomber scombrus): a kinematic analysis. J. exp. Biol. 109, 209-228.

Wardle, C. S., Videler, J. J. And Altringham, J. D. (1995). Tuning in to fish swimming waves: body form, swimming model and muscle function. J. exp. Biol. 198, 1629-1636.

ZaJAC, F. E. (1989). Muscle and tendon: Properties, models, scaling and application to biomechanics and motor control. Crit. Rev. biomed. Eng. 17, 359-411. 